\title{
REVERSING THE EXTRAVERTED LEADERSHIP ADVANTAGE: THE ROLE OF EMPLOYEE PROACTIVITY
}

\author{
ADAM M. GRANT \\ University of Pennsylvania \\ FRANCESCA GINO \\ Harvard University \\ DAVID A. HOFMANN \\ University of North Carolina at Chapel Hill
}

\begin{abstract}
Extraversion predicts leadership emergence and effectiveness, but do groups perform more effectively under extraverted leadership? Drawing on dominance complementarity theory, we propose that although extraverted leadership enhances group performance when employees are passive, this effect reverses when employees are proactive, because extraverted leaders are less receptive to proactivity. In Study 1, pizza stores with leaders rated high (low) in extraversion achieved higher profits when employees were passive (proactive). Study 2 constructively replicates these findings in the laboratory: passive (proactive) groups achieved higher performance when leaders acted high (low) in extraversion. We discuss theoretical and practical implications for leadership and proactivity.
\end{abstract}

Scholars have spent more than a century seeking to understand the characteristics of effective leaders (Zaccaro, 2007). Research now suggests that leading in an extraverted manner is a key to success. Extraversion is best understood as a tendency to engage in behaviors that place oneself at the center of attention, such as seeking status and acting dominant, assertive, outgoing, and talkative (Ashton, Lee, \& Paunonen, 2002). In a meta-analysis of the relationship between personality and leadership emergence and effectiveness, Judge, Bono, Ilies, and Gerhardt (2002: 765) found that extraversion is "the most consistent correlate of leadership across study settings and leadership criteria." Their results indicated that extraverted em-

For helpful feedback on drafts, we are grateful to Associate Editor Elizabeth Morrison, three anonymous reviewers, Jim Detert, Alison Fragale, Adam Galinsky, and Dave Mayer, as well as participants in the New Directions in Leadership Conference and the seminar series at the University of Toronto, University of British Columbia, Rice University, and the Tuck School of Business. For insightful discussions, we thank Brian Little and Susan Cain. For assistance with data collection and coding, we thank Andy Duvall, Jennifer Fink, Lisa Jones Christensen, Leslie Talbott, and Brett Yates. This article was accepted before Adam Grant became an associate editor for this journal.

Editor's Note: The manuscript for this article was accepted during Duane Ireland's term as editor. ployees are significantly more likely to (1) emerge as leaders in selection and promotion decisions and (2) be perceived as effective by both supervisors and subordinates. In another meta-analysis, Bono and Judge (2004) found that extraversion was the best personality predictor of "transformational leadership": leaders high in extraversion were more likely to express charisma, provide intellectual stimulation, and offer individualized consideration to their employees. Primary studies have further shown that extraversion is the only personality trait that predicts both typical and maximum ratings of transformational leadership performance (Ployhart, Lim, \& Chan, 2001), that the link between extraversion and transformational leadership can be traced to genetically heritable sources (Johnson, Vernon, Harris, \& Jang, 2004), and that U.S. presidents are perceived as more effective when they appear to be extraverted rather than introverted (Rubenzer \& Faschingbauer, 2004; Young \& French, 1996).

This research suggests that in leadership roles, extraverts have a clear advantage. However, scholars have begun to question whether this conclusion overstates the benefits of extraversion in leadership roles and overlooks the costs (Judge, Piccolo, \& Kosalka, 2009; McCormack \& Mellor, 2002). In particular, existing studies have focused on observers' perceptions of leadership effectiveness (Judge et al., 2002), overlooking the objective performance of the groups and organizations that leaders guide-a 
paramount indicator of leaders' actual effectiveness (Kaiser, Hogan, \& Craig, 2008). Accordingly, it is possible that although extraversion is a consistent predictor of supervisor and subordinate perceptions of leadership effectiveness, extraverted leadership may not always contribute positively to group performance. Research has shown that individuals tend to hold implicit theories of leaders as extraverts, suggesting that supervisor and subordinate evaluations of extraverted leaders may be enhanced by a "halo effect." This may occur because extraverted leaders match the prototypes of charismatic leaders that dominate both Western cultures (Lord, De Vader, \& Alliger, 1986) and Eastern cultures (Leung \& Bozionelos, 2004) and are especially prevalent in business (Agle, Nagarajan, Sonnenfeld, \& Srinivasan, 2006). Illustrating this point, in an online survey of over 1,500 senior leaders earning at least six-figure salaries, 65 percent viewed introversion as a barrier to leadership, and only 6 percent believed that introverts were more effective leaders than extraverts (Jones, 2006).

To advance theory, research, and practice on leader characteristics, it is critical to understand how they affect group performance (Kaiser et al., 2008). Our goal in this article is to examine the conditions under which extraverted leadership contributes to versus detracts from group performance. We propose that when employees are not proactive, extraverted leadership contributes to higher group performance, but when employees are proactive, this relationship reverses to a negative one. There is good reason to believe that in a changing business world, less extraverted leaders bring important strengths to the table. As organizational life becomes more dynamic, uncertain, and unpredictable, it has become increasingly difficult for leaders to succeed by merely developing and presenting their visions top-down to employees (Griffin, Neal, \& Parker, 2007). More than ever before, leaders depend on employees to proactively advance bottom-up change by voicing constructive ideas (Van Dyne \& LePine, 1998), taking charge to improve work methods (Morrison \& Phelps, 1999), and engaging in upward influence (Dutton, Ashford, O'Neill, \& Lawrence, 2001). However, research suggests that many leaders see these proactive behaviors as threats or distractions, and they thus fail to benefit from employees' contributions (Detert \& Burris, 2007; Grant, Parker, \& Collins, 2009; Parker, Williams, \& Turner, 2006; Seibert, Kraimer, \& Crant, 2001).

We expect that leaders who are low rather than high in extraversion are more receptive to bottom-up proactive behaviors from employees. As a result, we hypothesize that when employees are proactive, extraverted leadership is negatively rather than positively associated with group performance. We base these predictions on dominance complementarity theory (Carson, 1969; Kiesler, 1983), according to which high-quality interactions are facilitated when dominance and assertiveness from one party are balanced by compliance, obedience, and submissiveness from the other party. From this perspective, employees' proactive behaviors have the potential to complement the quiet, more reserved behavior of leaders low in extraversion, but challenge the authority of leaders high in extraversion.

In field and laboratory studies, we examine whether employee proactivity reverses the effect of extraverted leadership on group performance. In our first study, we use field data to examine whether a positive relationship between extraverted leadership and the profits of pizza delivery franchises is reversed when employees are proactive. In our second study, we use a laboratory experiment to test whether groups led in a highly extraverted manner perform better when employees are not proactive, while groups led in a less extraverted manner perform better when employees are proactive. The combination of field and laboratory data supports both the external and internal validity of our hypotheses, and we find parallel results across naturally occurring and experimentally manipulated variations in leaders' extraversion and employees' proactivity for predicting two objective performance outcomes: profits and output.

Our research makes important theoretical contributions to the literatures on leadership and proactivity, offering a more balanced perspective that recognizes both the strengths and weaknesses of extraverted leadership. First, we highlight how leadership research can gain traction by attending to how follower behaviors-and leader reactions to these behaviors-create a context that alters the impact of leader characteristics. Our studies document that leader extraversion can be either an asset or a liability for group performance, depending on the degree to which employees are proactive. In doing so, we show how leadership research can benefit from careful consideration of an expanded set of outcomes focusing on group performance, not only on leader emergence and perceived effectiveness. Second, we provide a theoretical and an empirical account of how employees' proactive behaviors are not only caused by leader characteristics; they can also moderate the effects of leader characteristics. This perspective accentuates the value of examining the group performance consequences of proactivity. Third, our findings reveal a potential 
irony of modern organizational life: although organizations often promote both extraverted leadership and employee proactivity, these two characteristics in combination may yield suboptimal group performance. Our research suggests that group performance is maximized when highly extraverted leadership is paired with less proactive employee behavior, or when less extraverted leadership is matched with more proactive employee behavior.

\section{EXTRAVERTED LEADERSHIP AND GROUP PERFORMANCE}

The purpose of this article is to examine contingencies that moderate the relationship between extraverted leadership and group performance. By group performance, we refer to the effectiveness of a unit in achieving collective goals (Campbell, 1990). To specify the characteristics that define extraverted leadership, it is important to gain a deeper understanding of personality. Psychologists have developed two different approaches to conceptualizing personality (Hogan, 1991). The trait view of personality emphasizes the underlying psychological processes, or cognitive and affective tendencies, that cause stability in individual characteristics over time or across situations (House, Shane, \& Herold, 1996; McCrae \& Costa, 1990). The behavioral view of personality emphasizes the overt, observable actions in which individuals engage over time or across situations (Buss \& Craik, 1983). Recently, psychologists have theoretically and empirically integrated these approaches by demonstrating that traits can be conceptualized as density distributions of "behavioral acts" (Fleeson, 2001). Behavioral acts are the building blocks of traits, and the stronger an individual's propensity toward a trait, the more frequently and intensely the individual enacts a corresponding set of behaviors (Fleeson, 2001). This integration of traits and behavioral acts is consistent with longstanding evidence showing that the same content dimensions and descriptors underlie both traits and behavioral acts and that the boundary between the two is fuzzy rather than categorically discrete (for a review, see Chaplin, John, and Goldberg [1988]).

Given the value of both trait and behavioral approaches to personality, our focus is on how leader characteristics-which capture both leaders' traits and their behaviors-affect group performance. In particular, we are interested in the leader characteristic of extraversion. Psychologists have long recognized that extraversion is one of the fundamental dimensions along which personality varies (e.g., Eysenck, 1973; Fleeson, 2001). Although scholars have debated about the defining features of extraversion, recent research suggests that "the real core" of extraversion is "the tendency to behave in ways that attract social attention" (Ashton et al., 2002: 245). To do so, extraverted individuals often seek out status and act assertive, interpersonally dominant, talkative, and outgoing (Caspi, Roberts, \& Shiner, 2005; DeYoung, Quilty, \& Peterson, 2007; Trapnell \& Wiggins, 1990). A number of organizational scholars have identified these qualities as critical to leadership (e.g., Bass, 1990; Kirkpatrick \& Locke, 1991; Mann, 1959; Yukl, 1998), and some neurobiologists have even described "the enjoyment of leadership roles" as a prototypical feature of extraversion (Depue \& Collins, 1999: 492). As noted previously, extensive evidence suggests that extraverted individuals are more likely to emerge as leaders, receive high ratings of effectiveness from supervisors and subordinates, and display transformational behaviors (for reviews, see Bono and Judge [2004], Judge et al. [2002], and Ones and Dilchert [2009]). An extraverted leadership style often involves engaging with followers, building networks, and influencing others with effective inspiration and ingratiation strategies (e.g., Cable \& Judge, 2003; House \& Howell, 1992).

Our contribution lies in introducing employee proactivity as a boundary condition for the extraverted leadership advantage outlined above. We predict that when employees are proactive, they may be more effective when their leaders are less extraverted. Proactive behaviors are anticipatory actions that employees take to create change (Crant, 2000; Grant \& Ashford, 2008). Because leaders cannot always predict, envision, and control key internal and external events, they rely on employees to take initiative to create constructive change (Griffin et al., 2007). Among the most widely studied proactive behaviors are voice, taking charge, and upward influence (Grant et al., 2009; Parker \& Collins, 2010). Voice refers to speaking up with useful suggestions (Van Dyne \& LePine, 1998). Taking charge refers to exercising initiative to improve work structures, processes, methods, and practices (Morrison \& Phelps, 1999). Upward influence refers to making active attempts to persuade leaders to endorse and implement changes (Dutton et al., 2001; Kipnis \& Schmidt, 1988). When employees engage in these behaviors, they exercise proactivity; when they do not engage in these behaviors, in keeping with prior research, we describe their actions as passive (Crant, 2000; Parker et al., 2006). We use the term passive not to denote a lack of energy and effort, but rather to capture reacting to others' visions and ideas instead of initiating one's own (Crant, 2000; Grant \& Ashford, 2008). 
To explain group performance, we conceptualize and study employee proactivity at the group level. Although proactivity is often measured in terms of individual-level behaviors, empirical findings have begun to converge around the view that proactivity can exist as a group-level phenomenon (Grant \& Ashford, 2008). Researchers have demonstrated the existence of team-level proactivity (Kirkman \& Rosen, 1999), firm-level proactivity (Aragon-Correa, 1998; Henriques \& Sadorsky, 1999), proactive "climates" (Fay, Lührmann, \& Kohl, 2004), and "climates for initiative" (Baer \& Frese, 2003). Theoretically, work groups are likely to develop norms for high levels of proactivity under contextual conditions of environmental uncertainty, interdependence, and autonomy. When environmental uncertainty is high, there is widespread recognition that employees need to be more proactive in order to anticipate and act upon threats and opportunities (Griffin et al., 2007). Furthermore, when interdependence is high, employees are more likely to coordinate their levels of proactivity to facilitate task completion (Griffin et al., 2007). In addition, research has shown that when employees are given autonomy, they often work together to coordinate efforts to take charge, undertaking collaborative activities to improve work processes and methods (Leana, Appelbaum, \& Shevchuk, 2010). Thus, depending on uncertainty, interdependence, and autonomy, different work groups can develop norms for different levels of proactivity.

\section{A Dominance Complementarity Perspective}

Drawing on dominance complementarity theory, we propose that when employees engage in proactive behaviors, extraverted leadership is negatively rather than positively associated with group performance. According to dominance complementarity theory (Carson, 1969; Kiesler, 1983), effective interactions are achieved when dominant, assertive behavior from one party is matched by submissive, passive behavior from another. A core tenet of dominance complementarity is that people seek balance in interpersonal interactions (Leary, 1957): when one acts dominant, the other is expected to act submissive, and this pairing allows them to coordinate their actions and interactions effectively. Kiesler (1983: 198) proposed that complementarity exists when the individual "contextually recognized as being superior is in the 'one-up' or primary position, whereas the person recognized as being inferior is in the 'one-down' or secondary position." Dominance complementarity represents the existence of a status hierarchy (Tiedens \& Fragale, 2003) in which both members are able to "confirm
... self-definitions" (Kiesler, 1983: 198). The dominant parties gain validation of their power and status, and the submissive parties gain support and security. For both parties, uncertainty about authority roles is reduced, preventing conflict and competition and facilitating the pursuit of common goals (Bendersky \& Hays, in press; Tiedens, Chow, \& Unzueta, 2007; Wiltermuth, 2009). When complementarity is lacking, individuals often focus on jockeying for position, which can create anxiety and distract attention and energy away from task completion (Smelser, 1961).

As a result, matching dominance and submissiveness can have important consequences for group performance. As Kristof-Brown, Barrick, and Stevens (2005: 939) explained, "There is extensive evidence that complementarity in dominance (a component of extraversion) and submissiveness is related to higher quality interpersonal interactions." Studies have shown that individuals, dyads, and groups achieve greater productivity when dominance complementarity exists, wherein more extraverted and dominant members work with more introverted and submissive members (e.g., Ghiselli \& Lodahl, 1958; Hoffman \& Maier, 1961; Kristof-Brown et al., 2005; Smelser, 1961). However, these studies have focused primarily on peer relationships, overlooking how dominance complementarity applies to hierarchical relationships between leaders and followers.

We extend dominance complementarity theory to inform the interplay of extraverted leadership and employee proactivity. As noted previously, highly extraverted leadership typically involves engaging in dominant, assertive behaviors and avoiding quieter, more reserved behaviors (see also McCrae \& Costa, 1989). Employees' proactive behaviors can be viewed as a form of dominance. Researchers have defined proactivity as an exercise of control (Frese, Garst, \& Fay, 2007; Parker et al., 2006), an expression of agency (Grant \& Ashford, 2008; Grant \& Parker, 2009), and an effort to change and challenge the status quo (Crant \& Bateman, 2000; Van Dyne, Cummings, \& McLean Parks, 1995). Voicing ideas, taking charge, and exerting upward influence are all displays of assertiveness. As a result, dominance complementarity theory suggests that the more extraverted a leader is, the less employees will perceive him or her as receptive to their proactive ideas and suggestions. Perceptions of leader receptivity refer to the degree to which employees view leaders as open to and willing to implement changes (Ashford, Rothbard, Piderit, \& Dutton, 1998; Detert \& Burris, 2007).

Employees are likely to perceive more extraverted leaders as less receptive to proactivity. Ac- 
cording to dominance complementarity theory, when one party acts dominant, he or she expects the other party to accept a lower-status position and communicate in a more submissive manner (Kiesler, 1983). Building on this logic, extraverted leaders may respond to employee proactivity as a threat, seeking out dominance and communicating in assertive, forceful ways. In contrast, less extraverted leaders may be receptive to employee proactivity as a valuable source of input, communicating in ways that signal openness and interest. Below, we discuss how extraverted leadership may have negative implications for receptivity to employee proactivity using two conceptual lenses: status conflict and communication styles.

Status conflict. Researchers have frequently observed that employees' proactive behaviors can be threatening to leaders, as they have the potential to introduce unwelcome changes (Grant et al., 2009; Miceli \& Near, 1995), make leaders feel embarrassed, incompetent, or vulnerable by exposing their flaws and weaknesses (Morrison \& Milliken, 2000), and usurp leaders' authority by venturing "beyond what management wants their employees to do" (Frese \& Fay, 2001: 171). We predict that extraverted leaders will be especially prone to experiencing employees' proactive behaviors as threatening. Extraverted leaders tend to seek out status (Anderson, John, Keltner, \& Kring, 2001; Barrick, Stewart, \& Piotrowski, 2002), which allows them to maintain a hierarchy in which their assertiveness and dominance are complemented by obedience and submissiveness on the part of employees. When their status is threatened, extraverted leaders may be "willing to engage in conflict and to use defensive and/or unconstructive tactics with others" (Ames \& Flynn, 2007: 309). In general, extraverted leaders tend to exercise influence not by seeking ideas from others, but rather by gaining dominance over their employees (Peterson, Smith, Martorana, \& Owens, 2003) and using direct persuasion techniques to build others' commitment to their own ideas (Anderson, Spataro, \& Flynn, 2008; Cable \& Judge, 2003; Caldwell \& Burger, 1997). Thus, extraverted leaders may reject employees' proactive ideas in favor of their own existing practices.

In keeping with these arguments, Judge et al. (2009: 868) noted that extraverted leaders tend to "behave in bold, aggressive, and grandiose ways. They like to be the center of attention. ... As such, extraverted leaders may be less likely to solicit input from subordinates and colleagues, potentially alienating organizational members who prefer that attention and credit be shared." We thus predict that the combination of extraverted leader- ship and employee proactivity has the potential to create a power struggle, as both leaders and employees seek to gain control and exercise influence. To do so, extraverted leaders may dismiss employees' proactive behaviors or work harder to increase their own control and influence, focusing on claiming status and asserting their authority instead of facilitating effective group performance. Indeed, research suggests that seeking dominance and power is likely to discourage leaders from considering employees' perspectives (Galinsky, Magee, Inesi, \& Gruenfeld, 2006). Employees, in turn, are likely to feel rejected and slighted by leaders' lack of consideration for their ideas (McFarlin \& Sweeney, 1996), leading them to experience helplessness and powerlessness (Magee \& Galinsky, 2008).

In contrast, less extraverted leaders tend not to be as concerned with status and power (Anderson et al., 2001; Barrick et al., 2002), and they may be more receptive to employees' proactive behaviors. When employees take charge to introduce new work methods, less extraverted leaders may embrace their ideas, using them to develop more efficient and effective systems (Moon, Kamdar, Mayer, \& Takeuchi, 2008), correct errors in faulty procedures (Staw \& Boettger, 1990), and identify new techniques for preventing errors and problems in the future (Wall, Jackson, \& Davids, 1992). Furthermore, less extraverted leaders may take particular notice of employees' efforts to voice important problems, which can enhance group performance (Detert \& Burris, 2007; Van Dyne \& LePine, 1998), and respond to upward influence by mobilizing attention and effort toward solving problems, which can enable them to make meaningful changes with respect to strategically significant issues (Dutton et al., 2001).

Communication styles. In addition, less extraverted leaders may listen more carefully to employees' proactive ideas and suggestions. Whereas highly extraverted individuals tend to be assertive and confident in building visions and expressing ideas, individuals lower in extraversion tend to be quieter and more reserved (e.g., Fleeson, 2001; Gosling, John, Craik, \& Robins, 1998). Research indicates that on average, less extraverted individuals speak more quietly than their highly extraverted counterparts (Scherer, 1978), which suggests that less extraverted leaders' communication styles leave more room for employees to be proactive. Furthermore, less extraverted individuals tend to spend more time listening and less time talking (Ramsay, 1966), and feel more apprehensive about initiating communication in groups (Opt \& Loffredo, 2000) and speaking in public (Feingold, 1983). As a result, less extraverted leaders may send more ver- 
bal and nonverbal signals that they are open to proactivity and may take more time to hear and consider ideas and suggestions.

Of course, leaders are likely to derive the greatest benefits from these proactive behaviors when the ideas underlying them are relevant to organizational goals (Frese \& Fay, 2001). However, even when employees' proactive behaviors are not relevant to organizational goals, there are two reasons to believe that less extraverted leaders will respond to them in ways that enhance group performance. First, because less extraverted leaders listen more carefully, employees will be more likely to feel that their ideas are considered and appreciated, which will enhance and sustain their motivations to contribute (e.g., Dutton et al., 2001; McFarlin \& Sweeney, 1996). Second, even if employees' proactive suggestions are misguided, they can still facilitate constructive changes. Employees' proactive behaviors can introduce a novel perspective, which may "stimulate divergent attention and thought. As a result, even when they are wrong they contribute to the detection of novel solutions and decisions that, on balance, are qualitatively better" (Nemeth, 1986: 23). Accordingly, since less extraverted leaders may be more willing to listen to divergent opinions and perspectives, they may be more capable of using misguided ideas constructively, reinforcing for employees that their ideas are valued.

Perceived leader receptivity and group performance. We thus propose that when employees are proactive, more extraverted leaders will respond less receptively to ideas and suggestions. In turn, perceiving a lack of leader receptiveness will discourage employees from working hard on behalf of their leaders. From the standpoint of organizational support theory (Rhoades \& Eisenberger, 2002), when employees feel that leaders value their contributions, they reciprocate by working harder. Feeling valued strengthens employees' perceived obligation to contribute, increases their identification with leaders, and enhances their confidence that their contributions will be worthwhile and rewarded (Rhoades \& Eisenberger, 2002). Indeed, research has shown that when employees feel that their contributions are valued, they respond by increasing their effort (Grant, 2008; Grant \& Gino, 2010). When employees perceive that leaders are not receptive to their contributions, they feel less valued and thus less motivated to reciprocate.

Consequently, we predict that employees' perceptions of leaders' receptivity mediate the moderating effect of employee proactivity on the relationship between leaders' extraversion and group performance. When employees are proactive, highly extraverted leaders respond less receptively, which decreases employees' motivation to perform effectively. This sequence constitutes a first-stage moderation model (Edwards \& Lambert, 2007). Employee proactivity moderates the effect of leader extraversion on employees' perceptions of leader receptivity in such a way that employees only perceive highly extraverted leaders as less receptive under conditions of high proactivity. Employee proactivity threatens leaders' ability to be the center of attention, reducing their receptiveness to ideas and suggestions. Our predictions are summarized in the following hypotheses:

Hypothesis 1. Employee proactivity moderates the association between leader extraversion and group performance. When employees are passive, leader extraversion is positively related to group performance, but when employees are proactive, leader extraversion is negatively related to group performance.

Hypothesis 2. Employee perceptions of receptivity mediate the moderating effect of employee proactivity on the relationship between leader extraversion and group performance.

\section{Overview of the Present Research}

To test these hypotheses, we conducted two studies. Guided by the trait and behavioral approaches to personality, we operationalized extraversion in terms of leaders' traits (Study 1) and behavioral acts (Study 2). In Study 1, we tested Hypothesis 1 with multisource field data from pizza delivery stores. In Study 2, we conducted a laboratory experiment to constructively replicate our test of Hypothesis 1, support causal inferences, and test Hypothesis 2. Since our hypotheses rely on motivational mechanisms-when extraverted leaders are not receptive to proactive suggestions, employees are less motivated to put forth effort-it was important to use tasks in which motivation drives differences in performance. In both studies, to observe motivational effects on group performance, we focused on relatively structured, simple tasks in which motivation is a central determinant of performance. By contrast, more complex tasks open the door for ability to play a more central role (Locke \& Latham, 2002; Schmidt \& Hunter, 2004), potentially suppressing performance differences caused by variations in leader extraversion and employee proactivity. 


\section{STUDY 1: METHODS}

\section{Sample and Procedures}

We obtained data from a U.S. national pizza delivery company that runs franchises. The leaders in the company are the overall store managers ( 1 per store), who independently oversee all store operations, including inventory control, personnel hiring and scheduling, and management of supervisors. We sent questionnaires for leaders and employees to 130 stores and obtained complete data from 57, achieving a response rate of 43.1 percent. The respondents were 57 store leaders and 374 employees $($ mean $=6.56$ employees per store, minimum $=2$, maximum $=15$ ). Because of confidentiality concerns, we collected demographic and employment data using five-point scales. With respect to employment with the organization, 1.8 percent of respondents had been with the company for less than one year; 5.4 percent had been employed for one to three years; 37.5 percent had been employed for three to five years; 44.6 percent had been employed for five to ten years; and 10.7 percent had been employed for at least ten years. With respect to employment in their current store, 19.3 percent had been employed less than one year; 33.3 percent had been employed for one to three years; 28.1 percent had been employed for three to five years; 17.5 percent had been employed for five to ten years; and 1.8 percent had been employed for at least ten years.

\section{Measures}

Unless otherwise indicated, all items used a Likert-type scale anchored at 1, "to a very small extent," and 5, "to a great extent."

Group performance. We measured group performance in terms of each store's overall profitability during the seven weeks following survey completion, after controlling for the average price of pizza orders and worker hours. This lagged seven-week period allowed us to calculate the reliability of weekly profits, which demonstrated excellent internal consistency $(\alpha=.98)$. Store profits are the ultimate metric on which the company evaluates leaders' performance, and it is the basis on which leaders are rewarded. It was important to control for the average price of orders and worker hours because these variables heavily influence profitability but are largely determined by a store's location (e.g., college campus vs. urban street vs. rural town), which are factors beyond the control of leaders and employees. Controlling for these locationbased input factors allowed us to examine how features of internal operations that leaders and em- ployees could influence (i.e., delivery costs, food costs, labor costs, planning, scheduling) were affected by leaders' personality traits and employees' proactive behaviors.

Leaders' personality traits. Store leaders rated their own personality traits using ten items for each of the "Big Five" traits from Goldberg's (1992) adjective scale. The extraversion scale included adjectives such as "assertive," "talkative," "bold," "introverted" (reverse-scored), "reserved" (reversescored), and "energetic" ( $\alpha=.73)$. Although our hypotheses focused on extraversion, since this trait is correlated with other Big Five traits (e.g., Olson, 2005), to reduce the likelihood of spurious associations, we controlled for the other four traits: emotional stability, agreeableness, openness, and conscientiousness. In particular, extraversion typically correlates positively with openness and emotional stability and also frequently correlates positively with agreeableness and conscientiousness (e.g., DeYoung et al., 2007; John \& Srivastava, 1999). To isolate the unique variance attributable to leader extraversion, it is important to control for these traits and their interactions with employee proactivity. The emotional stability scale included adjectives such as "relaxed," "touchy" (reverse-scored), "moody" (reverse-scored), "emotional" (reversescored), "high-strung" (reverse-scored), and "calm" ( $\alpha=.66)$. The agreeableness scale included adjectives such as "agreeable," "cooperative," "cold" (reverse-scored), "helpful," "rude" (reverse-scored), and "considerate" ( $\alpha=.75)$. The openness scale included adjectives such as "imaginative," "creative," "intellectual," "innovative," "shallow" (reverse-scored), and "complex" ( $\alpha=.72)$. The conscientiousness scale included adjectives such as "organized," "dependable," "sloppy" (reverse-scored), "conscientious," "careless" (reverse-scored), and "systematic" $(\alpha=.76)$.

Group proactivity. Employees rated the average levels of proactive behaviors occurring in their store. Across the stores, 374 employees provided ratings of store proactivity. Specifically, each employee was asked to rate the "typical behavior of employees in your store (excluding the store manager)." With respect to level of measurement, these items represent a referent shift compositional model (Chan, 1998). We provide additional evidence justifying the aggregation of these scales to the store level below.

We measured taking charge using the five highest-loading items from the taking charge scale developed by Morrison and Phelps (1999), including "Try to bring about improved procedures for the work unit," "Try to correct a faulty procedure or practice," and "Try to implement solutions to 
TABLE 1

Study 1: Results of Confirmatory Factor Analysis of Proactivity Items ${ }^{a}$

\begin{tabular}{|c|c|c|c|c|c|}
\hline Model & $\chi^{2}$ & $d f$ & CFI & SRMR & $\Delta \chi^{2}$ \\
\hline 1. Three-factor model with latent higher-order proactivity factor & 232.49 & 62 & .94 & .04 & \\
\hline 2. Two-factor model a: Voice and taking charge on same factor & 417.54 & 64 & .87 & .06 & $\chi^{2}(2)=185.05^{* * *}$ \\
\hline 3. Two-factor model b: Taking charge and upward influence on same factor & 693.80 & 64 & .77 & .09 & $\chi^{2}(2)=461.31^{* * *}$ \\
\hline 4. Two-factor model c: Voice and upward influence on same factor & 606.19 & 64 & .80 & .09 & $\chi^{2}(2)=373.70^{* * *}$ \\
\hline 5. Single-factor model & 857.13 & 65 & .71 & 10 & $\chi^{2}(3)=624.64^{* * *}$ \\
\hline
\end{tabular}

${ }^{a}$ Values in bold indicate the best-fitting model.

${ }^{*} p<.05$

${ }^{* *} p<.01$

$* * * p<.001$

pressing organizational problems" (individuallevel $\alpha=$.86, store-level $\alpha=.87$ ). We measured voice using the four highest-loading items from the voice scale developed by Van Dyne and LePine (1998), which includes items such as "Speak up with ideas for new projects or changes in procedures," "Communicate opinions about work issues to others even if their opinions differ or others disagree," and "Develop and make recommendations concerning issues that affect this store" (individual-level $\alpha=.88$, store-level $\alpha=$.89). We measured upward influence using the four highestloading items adapted from the upward communication scale developed by Hofmann and Morgeson (1999), including "Discuss production issues with the store leader" and "Discuss work issues with the store leader" (individual-level $\alpha=.83$, store-level $\alpha=.80)$.

To examine whether it was appropriate to aggregate the three proactive behaviors into a higherorder proactivity construct, we conducted confirmatory factor analyses using EQS software version 6.1 with maximum-likelihood estimation procedures (e.g., Kline, 1998). We found that a threefactor model with a latent higher-order proactivity factor achieved acceptable fit with the data and significantly better fit than all alternative nested models. Table 1 presents these results. All factor loadings were statistically significant and ranged from .70 to .80 for taking charge, .58 to .82 for voice, and .71 to .91 for upward influence. The factor loadings for the three proactivity constructs on the higher-order proactivity factor were .83 for taking charge, .88 for voice, and .69 for upward influence. These results suggest that the three proactivity constructs could be analyzed as a single higher-order proactivity construct (individual-level $\alpha=.91$, store-level $\alpha=$.97).

In light of the referent shift compositional model, we also investigated the appropriateness of aggregating the measure of proactivity to the store level. The median $r_{\mathrm{wg}}$ value was .93. This indicates strong within-group agreement, justifying the view that store proactivity existed and could be aggregated to the group level (LeBreton \& Senter, 2008). A oneway analysis of variance (ANOVA) indicated that proactivity varied significantly across stores $(F[56$, $317]=1.43, p<.05)$. Interrater reliability between employees was moderate (ICC1 $=.06$, ICC2 $=.30$, both $p<.05$ ). In conjunction, these results indicate high agreement within stores, but relatively low variance between stores-perhaps because the stores operate in the same industry and do not differ dramatically in the contextual levels of uncertainty, interdependence, and autonomy that create variations in group proactivity. The limited degree of between-store variance served to attenuate our results at the store level and resulted in a conservative investigation of our hypotheses.

\section{STUDY 1: RESULTS AND DISCUSSION}

Means, standard deviations, and correlations for our key variables appear in Table 2 . We tested our hypotheses using the moderated regression procedures recommended by Aiken and West (1991). We standardized the leader personality and employee proactivity variables and then multiplied them to create interaction terms. In our regression analyses, we controlled for the average price of orders and worker hours, as well as for the other four Big Five personality traits and their interactions with each proactive behavior. Table 3 displays the results of our regression analyses. ${ }^{1}$ As specified in Hypothesis 1 , there was a significant interaction between

\footnotetext{
${ }^{1}$ We also conducted the analyses separately for taking charge, voice, and upward communication and found the same patterns, with one exception: a significant interaction between leader emotional stability and employee proactivity in predicting taking charge. Simple slopes indicated that leader emotional stability predicted higher group performance when employees did not take charge, but lower group performance when they did. Since this
} 
TABLE 2

Study 1: Descriptive Statistics and Correlations ${ }^{a}$

\begin{tabular}{|c|c|c|c|c|c|c|c|c|c|c|c|c|c|c|}
\hline Variable & Mean & s.d. & 1 & 2 & 3 & 4 & $\mathbf{5}$ & 6 & 7 & 8 & 9 & 10 & 11 & 12 \\
\hline $\begin{array}{l}\text { 1. Group } \\
\text { performance } \\
\text { (profits) }\end{array}$ & $\$ 6,206.78$ & $1,766.65$ & (.98) & & & & & & & & & & & \\
\hline $\begin{array}{l}\text { 2. Average price of } \\
\text { orders }\end{array}$ & $\$ 17.03$ & 1.70 & -.10 & & & & & & & & & & & \\
\hline 3. Worker hours & 465.58 & 86.82 & $.83^{* * *}$ & -.22 & & & & & & & & & & \\
\hline $\begin{array}{l}\text { 4. Leader } \\
\text { extraversion }\end{array}$ & 3.76 & 0.57 & .05 & $.29 *$ & .08 & $(.73)$ & & & & & & & & \\
\hline $\begin{array}{l}\text { 6. Leader } \\
\text { agreeableness }\end{array}$ & 4.04 & 0.52 & -.15 & -.02 & -.05 & .10 & $.34^{* *}$ & * $(.75)$ & & & & & & \\
\hline 7. Leader openness & 3.76 & 0.54 & -.17 & .18 & -.15 & $.36 * *$ & -.08 & .16 & $(.72)$ & & & & & \\
\hline $\begin{array}{l}\text { 8. Leader } \\
\text { conscientiousness }\end{array}$ & 4.05 & 0.52 & -.26 & -.04 & -.03 & $.35 * *$ & .08 & $.33^{* *}$ & * $.43^{* *}$ & $(.76)$ & & & & \\
\hline $\begin{array}{l}\text { 9. Store taking } \\
\text { charge }\end{array}$ & 3.28 & 0.41 & .06 & .12 & .06 & .10 & -.10 & -.05 & .05 & .19 & $(.86 / .87)$ & & & \\
\hline 12. Store proactivity & 3.45 & 0.37 & .01 & .07 & .07 & .03 & .03 & .11 & .00 & .22 & $.81 * * *$ & $.85^{* * *}$ & $.84^{* * *}$ & $(.91 / .97)$ \\
\hline
\end{tabular}

${ }^{a} n=57$ (57 stores for variables 1-3, 57 store leaders for variables 4-8, and 374 employees for variables 9-12). Variables 3-11 are measured on a five-point Likert-type scale. Cronbach's alphas appear in parentheses on the diagonal. For the group proactivity measures (9-12), the first coefficient is the individual-level internal consistency, and the second is the store-level internal consistency.

leaders' extraversion and employee proactivity in predicting store profits. To interpret the form of the interaction, we plotted the simple slopes for the relationship between leaders' extraversion and store profits at one standard deviation above and below the mean of employee proactivity (see Figure 1). When employees engaged in low proactivity, extraverted leadership was associated with higher store profits $(\beta=.25, p<.02)$. When employees engaged in high proactivity, the simple slopes indicated that extraverted leadership was associated with lower store profits $(\beta=-.23, p<.05)$. Thus,

was not a hypothesized interaction and it did not emerge for the other two proactive behaviors, it is important to be cautious in interpreting it, as it may be a methodological artifact. However, if it can be replicated, one explanation is that leaders low in emotional stability experience levels of anxiety that can be productive or counterproductive, depending how they manage their anxiety (e.g., Norem \& Cantor, 1986; Tamir, 2005). When employees take charge, leaders low in emotional stability may be able to channel their anxiety in the productive direction of supporting, honing, and scaling up the development and implementation of new work processes. Voice and upward influence, because they involve verbal communications but not necessarily action taken to develop and implement a concrete change in work processes, may maintain uncertainty and thus fail to give leaders a clear focus for channeling their anxiety into constructive improvements. extraverted leadership predicted higher store performance when employees were passive, but lower store performance when employees were proactive.

These results show that employee proactivity moderates the relationship between leaders' extraversion and group performance, and the form of this moderating effect is consistent with the dominance complementarity perspective. Although these results are promising, they suffer from several limitations, including a small sample size and modest response rate, moderate between-store variance in proactivity, and an unusual coefficient for conscientiousness. As such, it was important to examine whether the results could be constructively replicated (Lykken, 1968) in a different sample with different operationalizations of leadership, employee proactivity, and group performance. In particular, we measured leaders' extraversion as a trait, but it was important to test whether our findings held when extraversion was operationalized as a set of behaviors. This investigation appeared especially worthwhile in light of evidence that leaders' traits have their impact through their expression in overt behaviors that mediate the relationship between traits and performance (e.g., Anderson \& Schneier, 1978). In addition, our observational data did not support causal inferences, and we were not able to measure the proposed mediating mechanism of perceived leader receptivity. Furthermore, employees might communicate proactivity differently to more versus less extraverted leaders. 
TABLE 3

Study 1: Moderated Regression Analyses Predicting Group Performance ${ }^{\mathrm{a}}$

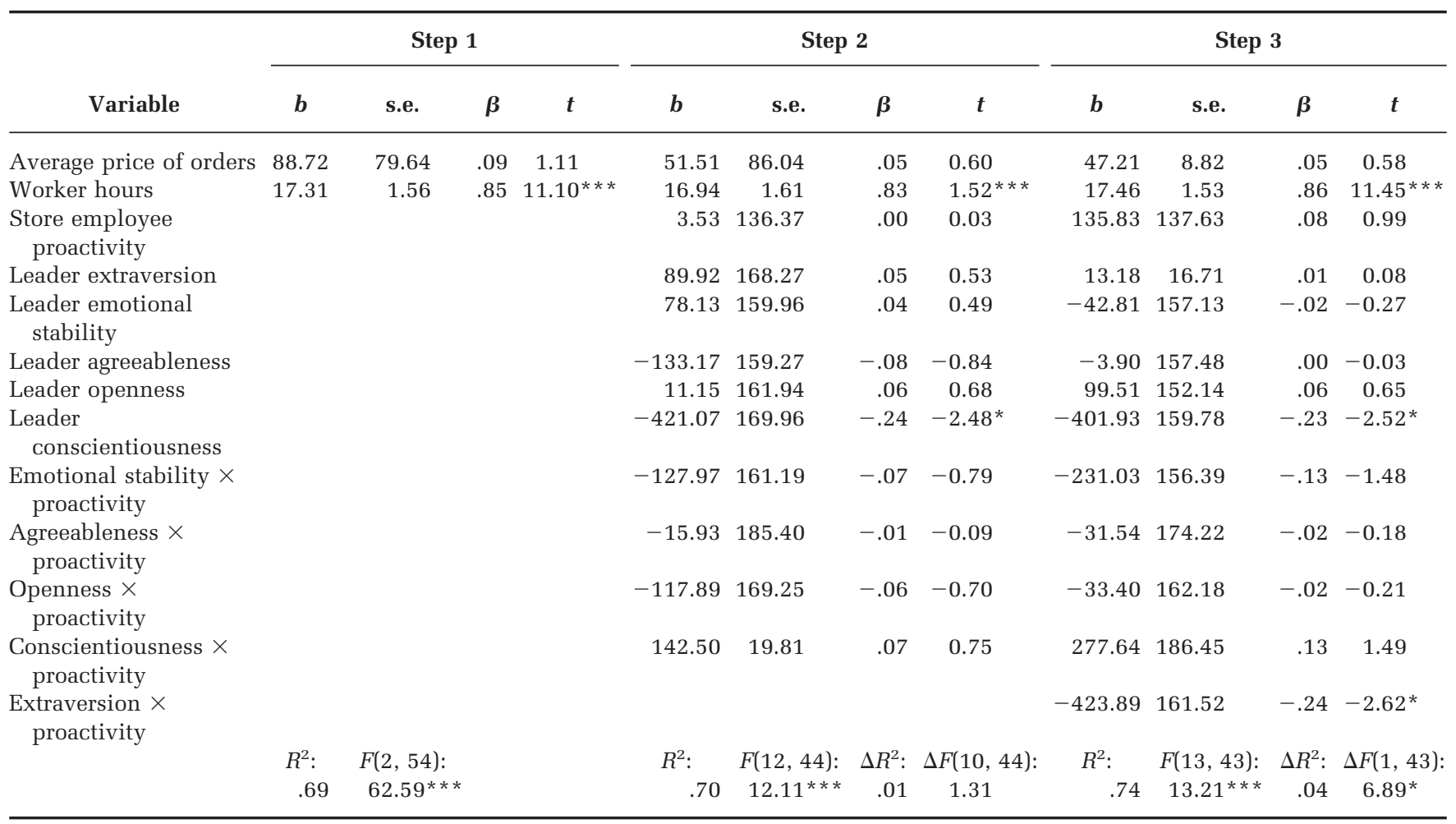

a $n=57$. Future research is necessary to explain why leaders' conscientiousness predicted lower store profits. Since conscientiousness scores were positively skewed, the pattern may be a partial function of restricted range, whereby the majority of leaders are above the threshold necessary for effective leadership. Moderately high leader conscientiousness may be optimal: extremely high scores may signal a level of detail orientation that distracts attention away from bigger-picture issues, a tendency to micromanage employees, or excessive cautiousness, risk aversion, and resistance to change (Judge et al., 2009; Le, Oh, Robbins, Ilies, Holland, \& Westrick, 2011).

${ }^{*} p<.05$

$* * p<.01$

$* * * p<.001$

To address these issues, our second study used an experimental method to demonstrate that the interactions of extraverted leadership behaviors with employee proactivity caused variations in group performance. This experimental design also allowed us to test whether more extraverted leadership behaviors caused higher group performance when employees were passive, while less extraverted leadership behaviors caused higher group performance when employees were proactive. It also enabled us to hold constant the nature and form of employee proactivity to rule out the possibility that employees express their proactive behaviors as a function of leader characteristics. Furthermore, we tested Hypothesis 2 by examining the role of perceptions of leader receptivity in explaining the observed effects.

\section{STUDY 2: METHODS}

\section{Sample and Procedures}

One hundred sixty-three college students from a university in the southeastern United States (mean age $=20.90$, s.d. $=1.24 ; 101$ male, 62 female) participated in the study in exchange for credit in an introductory organizational behavior class. After explaining that we were interested in understanding the factors that influence group performance, we told participants that they would be leading a group of four members to fold as many T-shirts as possible in ten minutes. There were 56 groups, each of which contained three focal participants: a leader and two followers. In all groups, two additional undergraduate research assistants (both male) were present as confederates, posing as additional followers. These two confederates were instructed to fold approximately the same number of T-shirts in every session regardless of experimental condition, leaving variance in group performance attributable to the leader and the two other followers.

In each session, one participant selected a card from a hat identifying him/her as the leader. In fact, all cards read "leader," so that the first person who chose a card became the leader. The two other 
FIGURE 1

Study 1: Simple Slopes for Store Profits

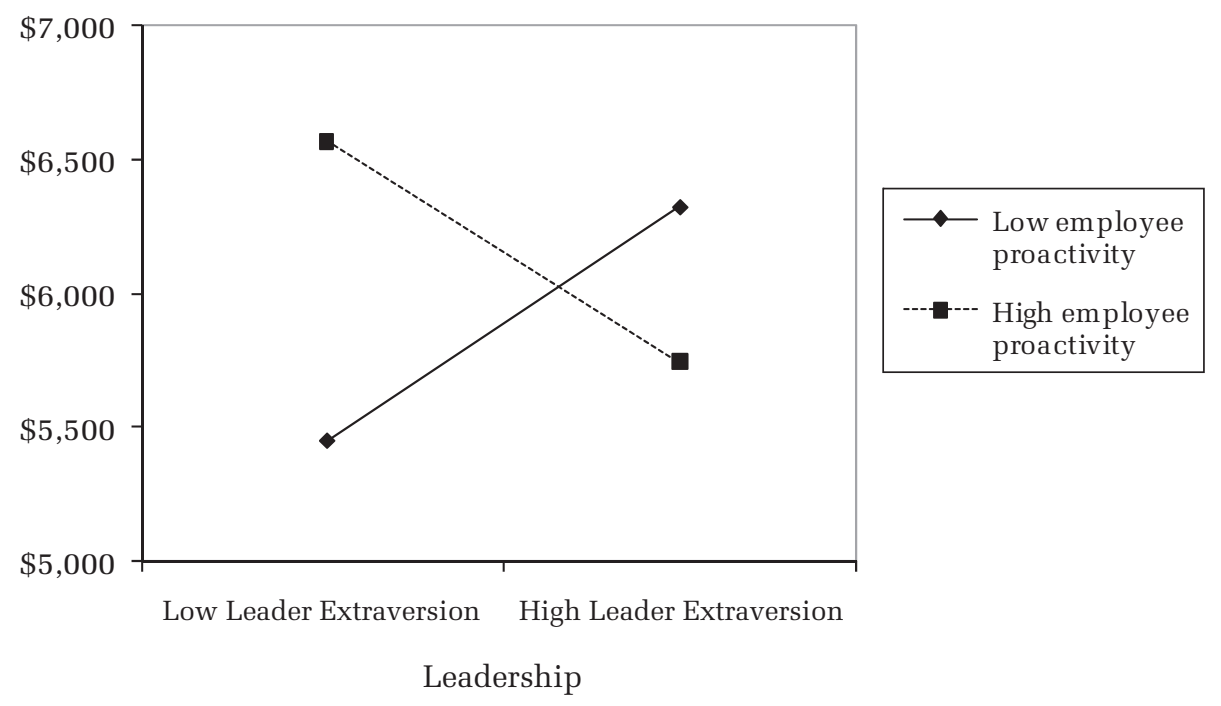

participants and the two confederates assumed the role of followers. To encourage participants to care about the outcome, we established instrumentality and valence by informing participants that the members of the groups in the top 10 percent of productivity would win iPod Nanos. We manipulated two factors between subjects: leaders' extraversion (high vs. low) and followers' proactive behavior (high vs. low).

Manipulation 1: Leaders' extraversion. We adapted procedures developed by Fleeson, Malanos, and Achille (2002) to temporarily manipulate participants' enactment of extraverted leadership behaviors. We asked participants to read a summary about why it is important for leaders to act in a manner indicating either high or low extraversion and then to write a short description of times when they had done so. In the high-extraversion condition, participants read about evidence for the importance of extraversion in leadership: "Scientific research now shows that behaving in an extraverted manner is the key to success as a leader. Like John F. Kennedy, Martin Luther King, Jr., and Jack Welch, great leaders are extraverted: their behavior is bold, talkative, and assertive. This enables them to communicate a strong, dominant vision that inspires followers to deliver results." The description then summarized the results of a meta-analysis showing "that extraversion is the most important trait of leaders and effective leadership" (Judge et al., 2002: 773) and provided highlights from several primary studies illustrating this pattern. Then, to make extraverted behavior more palatable, informed by research on self-persuasion (Heslin, Latham, \& VandeWalle, 2005), we asked partici- pants to reflect on a time when they had engaged in extraverted leadership: "Now, to get ready for your role, think of a time when you led a group effectively by acting bold, talkative, outgoing, and assertive. Write a paragraph about what you said and did, and why these behaviors helped to ensure the success of your group."

In the low-extraversion condition, participants read about evidence for the importance of a less extraverted leadership style: "Scientific research now shows that behaving in an introverted manner is the key to success as a leader. Like Mahatma Gandhi, Abraham Lincoln, and Socrates, great leaders are introverted: their behavior is quiet, shy, and reserved. This enables them to empower their people to deliver results." The description then summarized studies showing the potential costs of highly extraverted leadership behavior and the potential benefits of acting less extraverted (e.g., Judge et al., 2009; McCormack \& Mellor, 2002). Participants then reflected on a time when they had engaged in less extraverted leadership: "Now, to get ready for your role, think of a time when you led a group effectively by acting quiet, shy, and reserved. Write a paragraph about what you said and did, and why these behaviors helped to ensure the success of your group."

After they had completed the extraversion manipulation, the experimenter (a research assistant) asked leaders to explain the task to the two followers. The groups then started the task of folding T-shirts, timed by the experimenter. During the folding task, we introduced the manipulation of followers' proactive versus passive behavior. 
Manipulation 2: Followers' proactive behavior. During the folding task, we varied the degree to which the two confederate followers behaved proactively versus passively. In the passive condition, the two confederate followers simply acted according to the leader's instructions throughout the folding task. In the proactive condition, after 1 minute and 30 seconds, one of the confederates remarked, "I wonder if there's a more efficient way to do this." The other confederate then said to the leader, "Actually, I have a friend from Japan who has a faster way. It might take a minute or two to teach it, but do we want to try it?" We chose this proactive behavior because it involves elements of voice (speaking up with an idea), taking charge (introducing a new work method and process), and upward influence (attempting to change the leader's strategy). We also selected it as a prototypical example of a proactive behavior that had the potential to create improvements but required an investment of learning time up front.

If the leader said yes, the second confederate taught the new method to the group. If the leader said no, then the confederates continued with the traditional, slower method. The new method consisted of folding T-shirts as the task is often performed in Japan. The method involves laying the T-shirt flat, with the left sleeve pointing at one's body, and following these steps: (1) The right hand pinches the top next to the collar, (2) the left hand pinches in the middle of the shirt parallel to the first pinch, (3) the right hand folds the top to the bottom and (4) pinches the two together, (5) the right hand flips the T-shirt over and uncrosses the arms, and (6) the T-shirt is set down with the right sleeve folded under (see www.youtube.com/ watch $? \mathrm{v}=$ An0mFZ3enhM\&feature=related). Prior to the study, the confederate making the suggestion was trained to fold T-shirts according to this method, so that he could teach it to the rest of the group.

At the end of the session, the experimenter counted the number of T-shirts that the leader and two followers folded in the ten-minute period. The experimenter also counted the number of shirts the confederates folded so that their performance could be eliminated from the analyses. Confederate performance did not vary significantly by condition. Upon completion of the task, leaders completed a survey that assessed the extent to which they behaved in an extraverted manner during the task and the degree to which their followers were proactive. The followers also completed a survey asking them to assess leader extraversion, follower proactivity, and leader receptivity.

\section{Measures}

Dependent variable: Group performance. We measured group performance by counting the number of T-shirts each group had folded in the allocated period. Group performance is the sum of the leader and follower output; it does not include the number of T-shirts folded by the confederates.

Mediator: Leader receptivity. To measure perceived leader receptivity, we adapted items from existing measures of leader openness (Ashford et al., 1998; Detert \& Burris, 2007). We asked the followers to evaluate the leaders on five items ( $1=$ "disagree strongly," 7 = "agree strongly"): "open to new ideas," "receptive to suggestions," "interested in our ideas," "rejected new ideas" (reversescored), and "dismissed suggestions" (reversescored) $(\alpha=.94$ for follower 1 , and $\alpha=.89$ for follower 2). Since the two followers' ratings demonstrated good interrater reliability (ICC1 $=.70$, ICC2 $=.83, p<.001$ ), we averaged them to compute an overall score for perceived leader receptivity. We used this aggregate measure in the analyses presented below.

Manipulation check 1: Leaders' extraverted behavior. Leaders indicated the extent to which they displayed behaviors characteristic of extraverts during the task ( 1 = "extremely inaccurate," 9 = "extremely accurate"). We used Goldberg's (1992) 20-item adjective scale, which consisted of 10 positively worded items, including "assertive," "talkative," and "extraverted," and 10 reversescored items, such as "introverted," "quiet," and "shy" $(\alpha=.97)$. Followers also completed the same 20 -item scale to rate their leaders' extraversion ( $\alpha=$ .97 for both followers). Because the two followers achieved good interrater reliability (ICC1 $=.61$, ICC2 $=.76, p<.001$ ), we averaged their ratings.

Manipulation check 2: Followers' proactive behaviors. Leaders rated their followers' proactive behaviors by indicating the extent to which followers as a group displayed such behaviors $(1=$ "disagree strongly," 7 = "agree strongly"). We used a ten-item scale including items such as "Came up with ideas to improve the way in which the task was done" and "Put forward ideas to improve performance" ( $\alpha=.98)$. This scale was adapted from items developed by Griffin et al. (2007), Morrison and Phelps (1999), and Van Dyne and LePine (1998). The two followers also rated their team's proactivity using the same scale $(\alpha=.96$ for both followers). Since interrater reliability was good (ICC1 $=.81$ ICC2 $=.89, p<.001$ ), we averaged the two followers' ratings. 
TABLE 4

Study 2: Means and Standard Deviations by Condition for Key Variables ${ }^{a}$

\begin{tabular}{|c|c|c|c|c|}
\hline Condition & $\begin{array}{c}\text { Group } \\
\text { Performance }\end{array}$ & $\begin{array}{c}\text { Individual Follower } \\
\text { Performance }\end{array}$ & $\begin{array}{l}\text { Individual Leader } \\
\text { Performance }\end{array}$ & $\begin{array}{c}\text { Leader } \\
\text { Receptivity }\end{array}$ \\
\hline Low extraversion, passive followers & $137.64(48.30)$ & $50.32(19.86)$ & $52.07(15.27)$ & $4.50(1.13)$ \\
\hline Low extraversion, proactive followers & $175.43(30.22)$ & $59.64(10.80)$ & $56.14(11.13)$ & $5.35(0.87)$ \\
\hline High extraversion, proactive followers & $142.00(25.83)$ & $46.61(10.62)$ & $51.57(10.46)$ & $4.32(0.98)$ \\
\hline
\end{tabular}

${ }^{\text {a }}$ Standard deviations are in parentheses. $n=14$.

\section{STUDY 2: RESULTS AND DISCUSSION}

Means and standard deviations by condition for our focal variables appear in Table 4.

\section{Manipulation Checks}

We started by examining whether our leadership manipulation was effective using two (leader extraversion: high vs. low) times two (followers' behavior: proactive vs. passive) between-subjects ANOVAs. Followers rated leaders as more extraverted in the high-extraversion condition $($ mean $=5.42$, s.d. $=$ 1.49) than in the low-extraversion condition $($ mean $=4.19$, s.d. $=1.15 ; F[1,51]=10.65, p<.01$, $\left.\eta^{2}=.16\right)$. Leaders' ratings of their own extraversion during the task were consistent with the followers' ratings; leaders in the high-extraversion condition reported acting in a more extraverted manner (mean $=5.36$, s.d. $=1.80)$ than did those in the low-extraversion condition $($ mean $=4.21$, s.d. $=$ $1.41 ; F[1,52]=6.98, p<.02, \eta^{2}=.12$ ). Neither our proactivity manipulation nor the interaction between the two manipulations significantly affected these ratings.

We also used both leaders' and followers' ratings of followers' proactive behaviors to test the validity of our manipulation of followers' proactive behavior. As expected, leaders rated the behavior of followers in the proactive condition as more proactive (mean $=5.41$, s.d. $=1.03)$ than the behavior of followers in the passive condition (mean $=3.04$, s.d. $\left.=1.38 ; F[1,52]=52.40, p<.001, \eta^{2}=.50\right)$. Furthermore, followers in the proactive condition rated group proactivity as significantly higher (mean $=4.85$, s.d. $=0.43)$ than did the followers in the passive condition (mean $=2.78$, s.d. $=0.70$; $\left.F[1,51]=174.10, \eta^{2}=.76\right)$. Neither the extraverted leadership manipulation nor the interaction between the two manipulations had significant effects. Taken together, these results indicate that our manipulations were effective.

\section{Performance Effects}

We tested our hypotheses by conducting a 2 (leader extraversion) $\times 2$ (followers' proactive behavior) between-subjects ANOVA using the number of T-shirts a group folded as the dependent variable. We controlled for group size because five groups had four rather than five members (only one follower instead of two). The two main effects were not statistically significant. In keeping with Hypothesis 1 , we found a significant interaction between leaders' extraversion and followers' proactive behavior $\left(F[1,51]=7.17, p=.01, \eta^{2}=.12\right)$. Figure 2 is a graph of this interaction. Within each level of the proactivity manipulation, we used simple effects to examine whether groups led in a highly (less) extraverted manner performed better when the confederates were passive (proactive). When the confederates were passive, groups in the high-leader-extraversion condition (mean = 167.93 , s.d. $=24.31$ ) outperformed those in the low-leader-extraversion condition (mean $=137.64$, s.d. $=48.30 ; F[1,52]=5.70, p<.03)$. The reverse occurred when the confederates were proactive: groups with leaders in the low-extraversion condition (mean $=175.43$, s.d. $=30.22$ ) outperformed those whose leaders were in the high-extraversion condition $($ mean $=142.00$, s.d. $=25.83 ; F[1,52]=$ 6.95, $p<.02)$.

To ascertain whether these effects were driven by leader or follower performance, we conducted additional $2 \times 2$ between-subjects ANOVAs on the number of T-shirts folded by each leader and two followers. With follower performance as the dependent variable, the analyses showed a significant interaction between the leader extraversion and follower proactivity manipulations $(F[1,51]=6.38, p$ $\left.<.02, \eta^{2}=.11\right)$, and no other effects were significant. When the confederates were proactive, followers with leaders in the low-extraversion condition $($ mean $=59.64$, s.d. $=10.80)$ outperformed those with leaders in the high-extraversion condition $($ mean $=46.61$, s.d. $=10.62 ; F[1,52]=6.63$, $p=.01)$. When the confederates were passive, the 
FIGURE 2

Study 2: Results for Group Performance

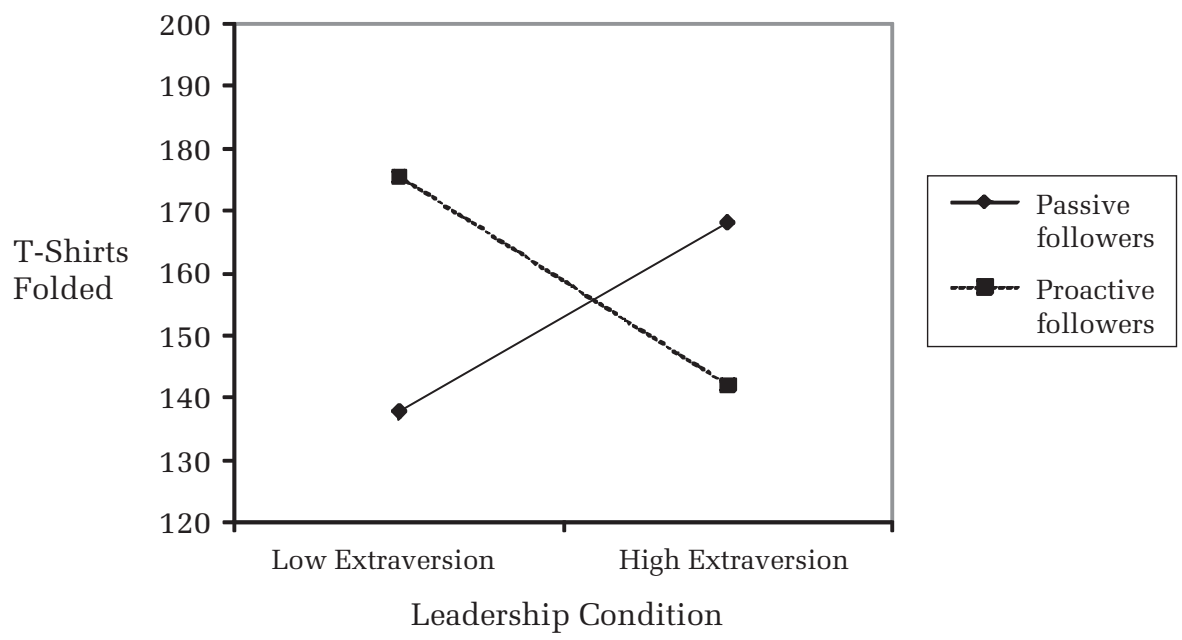

performance of followers with leaders in the highextraversion condition was higher (mean $=55.21$, s.d. $=9.70)$ than the performance of followers with leaders in the low-extraversion condition (mean = 50.32 , s.d. $=19.86$ ), but unlike the results for the full group's performance, the difference did not achieve statistical significance $(F[1,52]=0.93$, n.s). In contrast, the leader extraversion and follower proactivity manipulations had no significant main or interactive effects on leader performance. These analyses demonstrate that the differences in group performance caused by the interaction of leader extraversion and follower proactivity were due to followers' performance, not leaders' performance. Thus, supporting our hypotheses, when followers were proactive, they achieved higher performance when leaders acted in a less extraverted manner.

\section{Mediation Analyses}

To assess whether followers' perceptions of receptivity explained the interactive effects on group performance, we conducted moderated mediation analyses using the procedures recommended by Preacher, Rucker, and Hayes (2007) and Edwards and Lambert (2007). A $2 \times 2$ ANOVA showed that the interaction of leader extraversion and follower proactivity had a significant effect on followers' perceptions of leader receptivity $(F[1,51]=9.47, p$ $<.01, \eta^{2}=.15$ ), and the two main effects were not significant. Simple effects showed that as predicted, when the confederates were proactive, followers rated leaders in the low-extraversion condition as more receptive $($ mean $=5.35$, s.d. $=0.87$ ) than leaders in the high-extraversion condition (mean $=4.32$, s.d. $=0.98 ; F[1,52]=7.42, p<.01)$. When the confederates were passive, this pattern reversed: followers actually viewed leaders in the high-extraversion condition as more receptive (mean $=5.34$, s.d. $=1.01)$ than those in the lowextraversion condition $($ mean $=4.50$, s.d. $=1.13$; $F[1,52\}=4.98, p<.05)$. One explanation for this pattern is that when followers are passive, the shier, more reserved style of less extraverted leaders is interpreted as a lack of interest. When followers are proactive, on the other hand, this very style is interpreted as openness. These results show that as predicted, employee proactivity moderated the effect of leader extraversion on followers' perceptions of leader receptivity.

In a hierarchical regression analysis predicting follower performance, when we entered leader receptivity, the interactive effect of the leader extraversion and follower proactivity manipulations decreased to nonsignificance, and leader receptivity was a significant predictor of follower performance. Table 5 presents the results of this analysis. We completed the test of mediation by testing the size of the indirect effects of our manipulations on follower performance through perceived leader receptivity. We used bootstrap procedures to construct bias-corrected confidence intervals based on 1,000 random samples with replacement from the full sample (Shrout \& Bolger, 2002). The 95\% confidence interval for the indirect interaction effect through perceived leader receptivity excluded zero $(-0.89,-16.43)$, indicating statistical significance and supporting mediation of the moderating effect by perceived leader receptivity. Additional analyses showed that when the confederates were proactive, the $95 \%$ confidence interval for the indirect 
TABLE 5

Study 2: Results of Moderated Regression Analyses Predicting Follower Performance ${ }^{\mathrm{a}}$

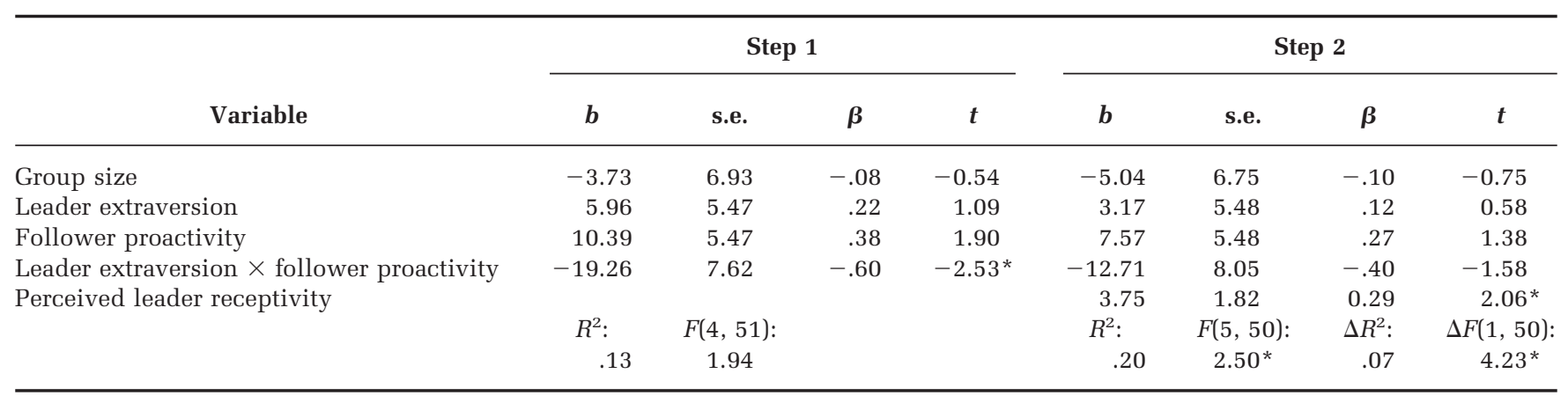

${ }^{\mathrm{a}} n=56$. When we entered the interaction term in a separate step between the first and second, variance explained increased by 11 percent, from $R^{2}=.02$ to $R^{2}=.13(F[1,51]=6.38, p<.02)$. We replicated these patterns of results for group performance (the sum of follower and leader T-shirts) as the dependent variable.

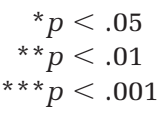

effect of leader extraversion on follower performance through perceived leader receptivity excluded zero $(-0.68,-17.68)$. In contrast, when the confederates were passive, the $95 \%$ confidence interval for the indirect effect of leader extraversion on follower performance through perceived receptivity included zero $(-3.66,1.53)$. The first-stage moderation effect was significantly stronger in the high proactivity condition than the low proactivity condition (95\% confidence interval for the differences: $0.21,1.60$ ), as was the overall indirect effect (95\% confidence interval for the differences: 0.27 , 15.79). These results support Hypothesis 2, showing that perceptions of leader receptivity mediated the moderating effect of employee proactivity on the relationship between leader extraversion and group performance.

\section{Alternative Explanation}

A rival account of our findings is that leaders in the high- (low-)extraversion condition were less (more) likely to adopt the proactive suggestion, and using an inferior (superior) method caused their groups to perform less (more) effectively. According to this perspective, followers' perceptions of leader receptivity may be a by-product of leaders' actual decisions about whether to accept or reject the proactive suggestion made by the confederates. To test this possibility, we examined the data within the proactive conditions. The proportions of leaders who accepted and adopted the new method were $8 / 14(57.1 \%)$ in the low-extraversion condition and 9/14 (69.2\%) in the high-extraversion condition, and these proportions did not differ statistically $\left(\chi^{2}[1]=0.42\right.$, n.s.). Thus, the extraversion manipulation did not influence the likelihood that leaders accepted and adopted the proactive suggestion.

Furthermore, the performance of the groups that adopted and did not adopt the new method did not significantly differ. Followers whose leader accepted the idea $($ mean $=161.82$, s.d. $=34.87)$ did not fold significantly more T-shirts than those whose leader rejected the idea (mean $=156.60$, s.d. $=29.26 ; t[25]=0.40$, n.s.). Our observations suggest that, although the new method had the potential to be more efficient, the ten-minute interval did not provide most teams with the opportunity to achieve this potential, as the time lost in teaching and learning the new method offset the potential gains.

These results rule out the alternative explanation that adopting a more effective or efficient method drove the differences in the performance of proactive groups in the high- versus low-leader-extraversion conditions. The moderated mediation analyses support our hypothesis that differences in perceived leader receptivity are what motivate the observed differences in performance. When the confederates were proactive, participants perceived the more extraverted leaders as less receptive to ideas, and they invested less effort in the task. ${ }^{2}$ In addition to supporting our proposed mo-

\footnotetext{
${ }^{2}$ This raises a critical question about how the leaders in the high-extraversion condition came to be perceived by followers as less receptive than their counterparts in the low-extraversion condition. Although further research is necessary to shed light on the relevant micromediators, the high-extraversion manipulation may have
} 
tivational mechanism of perceived leader receptivity, this study provides a conservative test of our overall hypotheses, as it shows that lower leader extraversion can improve the performance of proactive groups even when their ideas are not actually superior or more efficient.

\section{GENERAL DISCUSSION}

When does extraverted leadership contribute to higher group performance? In both a field and a laboratory study, we found that when employees were not proactive, extraverted leadership was associated with higher group performance. However, when employees were proactive, this pattern reversed, so that extraverted leadership was associated with lower group performance. We demonstrated this crossover interaction using two different measures of group performance, both naturally occurring and controlled proactive behaviors, and operationalizations of leader extraversion as a personality trait and a behavioral style. Our findings offer meaningful theoretical contributions to the literatures on leadership and proactivity in organizations.

\section{Theoretical Contributions}

Our primary contribution lies in identifying an important boundary condition for when groups led in an extraverted manner perform more effectively. Our research suggests that complementarity between leadership style and employee proactivity contributes to group performance. Specifically, the highest level of group performance was achieved either when a lack of proactivity from employees was paired with a more extraverted leadership style or when employee proactivity was paired with a less extraverted leadership style. Group performance was hindered when both employees and leaders acted in a more dominant, agentic manner (i.e., proactive employees, extraverted leader) and when neither employees nor leaders acted in this

encouraged leaders to interrupt more frequently, attempt to reassert their visions and authority, show less enthusiastic facial expressions, and actively discourage further ideas and suggestions, and the low-extraversion manipulation may have encouraged leaders to listen carefully and show their appreciation for followers' contributions. Because of these differences in receptive responses to the confederates' proactivity, followers with leaders in the high-extraversion condition may have felt less valued and thus less motivated to contribute, and followers with leaders in the low-extraversion condition may have felt more valued and thus more motivated to contribute. way (i.e., passive employees, less extraverted leader).

Our research represents a step toward theoretically integrating trait and contingency perspectives on leadership. The recent resurgence of research on leader characteristics has focused primarily on their direct associations with effectiveness outcomes (Judge et al., 2009); less research has examined contingencies that moderate these associations. A handful of studies have examined how leader extraversion moderates the relationship of leader-member exchange with performance and turnover (e.g., Bauer, Erdogan, Liden, \& Wayne, 2006) and strengthens the relationship between emotion recognition and transformational leadership (e.g., Rubin, Munz, \& Bommer, 2005). However, little research has identified contingencies that moderate the effects of extraverted leadership on group performance. In the spirit of classic contingency theories of leadership (e.g., Fiedler, 1971; Vroom \& Yetton, 1973), we introduced employee proactivity as an important contingency for the group performance effects of extraverted leadership. Our results provide an explanation for the reversal of the extraverted leadership advantage by showing that when employees are proactive, those who lead in a less extraverted style are viewed as more receptive to employee proactivity. By showing that followers' proactivity strengthens the performance of groups led by less extraverted individuals, our research lends conceptual and empirical rigor to assertions in the popular press that extraverted leadership is not necessarily a requirement for group and organizational effectiveness (Badaracco, 2002; Collins, 2001; Jones, 2006).

Our research also advances knowledge about proactivity in organizations. Researchers frequently assume that employees' proactive behaviors contribute to group performance but have rarely tested this assumption, focusing instead on the antecedents of proactive behaviors (Grant et al., 2009). The few studies that have examined the consequences of proactive behaviors have done so at the individual level, examining implications for employees' performance evaluations (e.g., Van Dyne \& LePine, 1998) and career success (e.g., Seibert et al., 2001). Although scholars have presented conceptual arguments that proactive behaviors facilitate higher group performance, little empirical research has tested these specific linkages (Grant \& Ashford, 2008; Griffin et al., 2007). Our research is among the first efforts to examine the group performance consequences of employees' proactive behaviors. We found that whether employees' proactive behaviors increase or decrease group performance depends on the degree to which their lead- 
ers act extraverted. Our research reveals how employees' proactive behaviors contribute to group performance when leaders are quiet and reserved but can actually undermine group performance when leaders are active and assertive. These results address calls to understand the conditions under which employees' proactive behaviors have a negative rather than positive impact on group performance (Grant \& Ashford, 2008).

Our findings thereby move toward synthesizing the literatures on leadership and proactivity, presenting a new perspective on employee proactivity as a contingency for leadership effects. Existing research has treated leadership as an antecedent of employees' proactive behaviors (e.g., Detert \& Burris, 2007; Griffin, Parker, \& Mason, 2010; Parker et al., 2006), overlooking the possibility that leadership interacts with employees' proactive behaviors to influence performance outcomes. Our studies provide new evidence that leadership is not only an influence on employee proactivity; its effects can also be shaped and altered by employee proactivity.

In addition, our research raises questions about whether job enrichment and empowerment interventions may have unintended consequences. A number of studies have shown that enriching jobs to provide autonomy and empowerment is associated with higher levels of employee proactivity (Grant \& Parker, 2009). However, this research has yet to examine how leaders' traits and styles affect the consequences of these proactive behaviors. Our studies point to the provocative possibility that when extraverted leaders enrich jobs to provide autonomy and empowerment, they may respond to employees' ensuing proactive behaviors in ways that undermine their potential to contribute to improved performance.

Finally, our research extends knowledge about the objective, not only the subjective, consequences of dominance complementarity theory. Previous studies have focused primarily on the psychological consequences of complementarity, including attraction, liking, cohesion, and observer performance ratings (e.g., Kristof-Brown et al., 2005; Fragale, Tiedens, \& Lee, 2003). In contrast, little research has linked dominance complementarity to objective performance outcomes, especially at the group level, which is also a critical oversight in leadership research (Kaiser et al., 2008). Our research begins to fill this gap by documenting the objective performance benefits of complementarity, operationalized in terms of the pairing of extraverted, assertive leadership with minimal employee proactivity or less extraverted, more reserved leadership with high employee proactivity.

\section{Limitations and Future Directions}

Our studies are subject to a number of limitations that suggest directions for future research. In both of our studies, leaders were in charge of groups responsible for relatively structured, repetitive, effort-based tasks (delivering pizzas and folding T-shirts). It remains to be seen whether the patterns generalize to more difficult, complex, or creative tasks. It is possible that differences in leader extraversion may have a stronger effect in more complex tasks-not only through the motivational mechanism of perceived leader receptivity, but also through the knowledge mechanism of enabling leaders to utilize better task strategies. Uncertainty about leader power and status (Kramer, 1998) may be another important boundary condition. When leaders have high "referent power" and high achieved or ascribed status, they may be open to proactivity regardless of their levels of extraversion, as they feel that their standing and authority are not being threatened. Similar predictions may be made for goal interdependence and value congruence, which may help to align leaders and employees around particular forms of proactivity that facilitate goal pursuit and value expression. In addition, our results may be circumscribed to relatively constructive forms of proactive behaviors. In Study 1, we did not measure whether employees' proactive behaviors were targeted in productive directions, and in Study 2, our confederates suggested an idea that had the potential to improve performance. Will less extraverted leaders still be receptive to more self-serving or destructive expressions of proactivity? Will more extraverted leaders be even less receptive to these forms of proactivity?

On a related note, extraversion is a multifaceted trait, and we did not unpack which particular facets were responsible for the effects observed. Is it dominance-assertiveness, sociability, or a combination of these facets that drives the different responses of leaders to employees' proactive behaviors? In addition, we did not test the psychological, behavioral, and social processes through which leaders with different levels of extraversion reacted differently to employees' proactive behaviors. It will be critical for researchers to test several mechanisms. Do less extraverted leaders listen more carefully? Are they more focused and less distracted? Do they experience proactivity as less egothreatening and actively encourage more proactivity? When employees are proactive, are less extraverted leaders less overconfident (see $\mathrm{Ng}$, Ang, \& Chan, 2008) or less overwhelmed by the social and intellectual demands of leadership roles (see 
Little \& Joseph, 2006; McGregor, McAdams, \& Little, 2006). We also did not examine the mechanisms through which leaders' reactions to employees' proactive behaviors influenced group performance. Further research will enable a deeper understanding of the explanatory processes underlying our findings.

Interestingly, our findings appear to contrast with research on leader prototypicality, which suggests that when leaders are viewed as similar to and representative of their groups, these groups perform more effectively (Lipponen, Koivisto, \& Olkkonen, 2005; van Knippenberg \& Hogg, 2003; van Knippenberg \& van Knippenberg, 2005). From this perspective, proactive employees may be particularly motivated when working with extraverted leaders who share their assertive tendencies. Although additional research is necessary to address this issue in further depth, one interpretation of the discrepancy is that employees' responses to prototypical leaders vary as a function of the content dimension under consideration. Employees may respond favorably to leaders who share their values, attitudes, beliefs, and characteristics, but dominance complementarity emerges with respect to behaviors that are zero-sum: it is difficult for highly extraverted leaders to be the center of attention when employees are proactive, and it is equally challenging for proactive employees to advance bottom-up change when highly extraverted leaders impose their ideas. Highly extraverted leaders and proactive employees have different goals and expectations about the degree of leader control versus employee input that is appropriate, which may be why prototypicality is not ideal with respect to these content dimensions. When proactive employees work with less extraverted leaders, on the other hand, the ensuing complementarity "establishes a reciprocal relationship in which both sides have their needs met. . . . This type of mutually fulfilling interaction is desirable to both sides" (KristofBrown et al., 2005: 939-940). If this interpretation is accurate, it suggests that leader prototypicality effects are bounded to dimensions of similarity that are not zero-sum and can be shared by both sides.

\section{Practical Implications and Conclusion}

Our research offers valuable practical insights for both leaders and employees. For leaders, our studies have three key implications. First, our findings provide less extraverted leaders with a new set of tools for directing their groups toward effective performance. The popular press is replete with suggestions for individuals low in extraversion to "build on their quiet strength" by practicing their public speaking skills (Kahnweiler, 2009), achieve the "introvert advantage" by smiling more frequently (Laney, 2002), leverage "introvert power" by taking breaks and scheduling time to think (Helgoe, 2008), and take their companies from "good to great" by being quiet and reserved but still strong-willed (Collins, 2001). In contrast to these speculations, our research highlights a theoretically sound, empirically supported strategy whereby less extraverted individuals can facilitate group performance: actively encourage proactive behaviors on the part of employees. By being receptive to employees' efforts to voice ideas, take charge to improve work methods, and exercise upward influence, less extraverted leaders can develop more efficient and effective practices that enhance group effectiveness.

Second, our findings may provide highly extraverted leaders with action steps for improving group performance. In settings and situations in which proactive suggestions are important, leaders who naturally tend to be assertive may wish to adopt a more reserved, quiet style. Since our laboratory experiment indicated that individuals can temporarily change their patterns of behavior, this prescription may be tenable. Third, in the spirit of developing future leaders, existing leaders may find it useful to train more extraverted managers to take notice of, utilize, recognize, and reward employees' proactive behaviors. Finally, for employees, our findings suggest that proactive behaviors may be more effective with quieter leaders who are more receptive. It may be wise, then, for employees to make particular efforts to voice suggestions, take charge, and exert upward influence when working with less extraverted leaders. Employees may also seek out such leaders as audiences for their proactive ideas. In conclusion, our findings reveal how leader extraversion can be a liability-not only an asset-for group performance.

\section{REFERENCES}

Agle, B. R., Nagarajan, N. J., Sonnenfeld, J. A., \& Srinivasan, D. 2006. Does CEO charisma matter? An empirical analysis of the relationships among organizational performance, environmental uncertainty, and top management team perceptions of CEO charisma. Academy of Management Journal, 49: 161-174.

Aiken, L. S., \& West, S. G. 1991. Multiple regression: Testing and interpreting interactions. Newbury Park, CA: Sage.

Ames, D. R., \& Flynn, F. J. 2007. What breaks a leader: The curvilinear association between assertiveness and leadership. Journal of Personality and Social Psychology, 92: 307-324.

Anderson, C., John, O. P., Keltner, D., \& Kring, A. M. 2001. 
Who attains social status? Effects of personality and physical attractiveness in social groups. Journal of Personality and Social Psychology, 81: 116-132.

Anderson, C., Spataro, S. E., \& Flynn, F. J. 2008. Personality and organizational culture as determinants of influence. Journal of Applied Psychology, 93: 702710.

Anderson, C. R., \& Schneier, C. E. 1978. Locus of control, leader behavior and leader performance among management students. Academy of Management Journal, 21: 690-698.

Aragon-Correa, J. A. 1998. Strategic proactivity and firm approach to the natural environment. Academy of Management Journal, 41: 556-567.

Ashford, S. J., Rothbard, N. P., Piderit, S. K., \& Dutton, J. E. 1998. Out on a limb: The role of context and impression management in selling gender-equity issues. Administrative Science Quarterly, 43: 23-57.

Ashton, M. C., Lee, K., \& Paunonen, S. V. 2002. What is the central feature of extraversion? Social attention versus reward sensitivity. Journal of Personality and Social Psychology, 83: 245-251.

Badaracco, J. L., Jr. 2002. Leading quietly: An unorthodox guide to doing the right thing. Boston: Harvard Business School Press.

Baer, M., \& Frese, M. 2003. Innovation is not enough: Climates for initiative and psychological safety, process innovations, and firm performance. Journal of Organizational Behavior, 24: 45-68.

Barrick, M. R., Stewart, G. L., \& Piotrowski, M. 2002. Personality and job performance: Test of the mediating effects of motivation among sales representatives. Journal of Applied Psychology, 87: 43-51.

Bass, B. M. 1990. Bass and Stogdill's handbook of leadership. New York: Free Press.

Bauer, T. N., Erdogan, B., Liden, R. C., \& Wayne, S. J. 2006. A longitudinal study of the moderating role of extraversion: Leader-member exchange, performance, and turnover during new executive development. Journal of Applied Psychology, 91: 298-310.

Bendersky, C., \& Hays, N. A. In press. Status conflict in groups. Organization Science.

Bono, J. E., \& Judge, T. A. 2004. Personality and transformational and transactional leadership: A meta-analysis. Journal of Applied Psychology, 89: 901-910.

Buss, D. M., \& Craik, K. H. 1983. The act frequency approach to personality. Psychological Review, 90: 105-126.

Cable, D. M., \& Judge, T. A. 2003. Managers' upward influence tactic strategies: The role of manager personality and supervisor leadership style. Journal of Organizational Behavior, 24: 197-214.

Caldwell, D. F., \& Burger, J. M. 1997. Personality and social influence strategies in the workplace. Person- ality and Social Psychology Bulletin, 23: 10031012.

Campbell, J. P. 1990. Modeling the performance prediction problem in industrial and organizational psychology. In M. D. Dunnette \& L. M. Hough (Eds.), Handbook of industrial and organizational psychology (2nd ed.): 687-732. Palo Alto, CA: Consulting Psychologists Press.

Carson, R. C. 1969. Interaction concepts of personality. Chicago: Aldine.

Caspi, A., Roberts, B. W., \& Shiner, R. L. 2005. Personality development: Stability and change. In S. T. Fiske, A. E. Kazdin, \& D. L. Schacter (Eds.), Annual review of psychology, vol. 56: 453-484. Palo Alto, CA: Annual Reviews.

Chan, D. 1998. Functional relations among constructs in the same content domain at different levels of analysis: A typology of compositional models. Journal of Applied Psychology, 83: 234-246.

Chaplin, W. F., John, O. P., \& Goldberg, L. R. 1988. Conceptions of states and traits: Dimensional attributes with ideals as prototypes. Journal of Personality and Social Psychology, 54: 541-557.

Collins, J. C. 2001. Good to great: Why some companies make the leap... and others don't. New York: HarperBusiness.

Crant, J. M. 2000. Proactive behavior in organizations. Journal of Management, 26: 435-462.

Crant, J. M., \& Bateman, T. S. 2000. Charismatic leadership viewed from above: The impact of proactive personality. Journal of Organizational Behavior, 21: $63-75$.

Depue, R. A., \& Collins, P. F. 1999. Neurobiology of the structure of personality: Dopamine, facilitation of incentive motivation, and extraversion. Behavioral and Brain Sciences, 22: 491-569.

Detert, J. R., \& Burris, E. R. 2007. Leadership behavior and employee voice: Is the door really open? Academy of Management Journal, 50: 869-884.

DeYoung, C. G., Quilty, L. C., \& Peterson, J. B. 2007. Between facets and domains: 10 aspects of the Big Five. Journal of Personality and Social Psychology, 93: $880-896$.

Dutton, J. E., Ashford, S. J., O’Neill, R. M., \& Lawrence, K. A. 2001. Moves that matter: Issue selling and organizational change. Academy of Management Journal, 44: 716-736.

Edwards, J. R., \& Lambert, L. S. L. 2007. Methods for integrating moderation and mediation: A general analytical framework using moderated path analysis. Psychological Methods, 12: 1-22.

Eysenck, H. J. 1973. Eysenck on extraversion. Oxford, U.K.: Halsted.

Fay, D., Lührmann, H., \& Kohl, C. 2004. Proactive climate in a post-reorganization setting: When staff compen- 
sate managers' weaknesses. European Journal of Work and Organizational Psychology, 13: 241-267.

Feingold, A. 1983. Correlates of public speaking attitude. Journal of Social Psychology, 120: 285-286.

Fiedler, F. E. 1971. Validation and extension of the contingency model of leadership effectiveness: A review of empirical findings. Psychological Bulletin, 76: $128-148$.

Fleeson, W. 2001. Toward a structure- and process-integrated view of personality: Traits as density distributions of states. Journal of Personality and Social Psychology, 80: 1011-1027.

Fleeson, W., Malanos, A. B., \& Achille, N. M. 2002. An intraindividual process approach to the relationship between extraversion and positive affect: Is acting extraverted as "good" as being extraverted? Journal of Personality and Social Psychology, 83: 14091422.

French, J. R. P., \& Raven, B. 1959. The bases of social power. In D. Cartwright \& A. Zander (Eds.), Group dynamics: Research and theory: 150-167. New York: Harper \& Row.

Frese, M., \& Fay, D. 2001. Personal initiative: An active performance concept for work in the 21st century. In B. M. Staw \& R. Sutton (Eds.), Research in organizational behavior, vol. 23: 133-187. Greenwich, CT: JAI Press.

Frese, M., Garst, H., \& Fay, D. 2007. Making things happen: Reciprocal relationships between work characteristics and personal initiative in a four-wave longitudinal structural equation model. Journal of Applied Psychology, 92: 1084-1102.

Galinsky, A. D., Magee, J. C., Inesi, M. E., \& Gruenfeld, D. H. 2006. Power and perspectives not taken. Psychological Science, 17: 1068-1074.

Ghiselli, E. E, \& Lodahl, T. M. 1958. The evaluation of foremen's performance in relation to the internal characteristics of their work groups. Personnel Psychology, 11: 179-187.

Goldberg, L. R. 1992. The development of markers for the Big-Five factor structure. Psychological Assessment, 4: 26-42.

Gosling, S. D., John, O. P., Craik, K. H., \& Robins, R. W. 1998. Do people know how they behave? Self-reported act frequencies compared with on-line codings by observers. Journal of Personality and Social Psychology, 74: 1337-1349.

Grant, A. M. 2008. The significance of task significance: Job performance effects, relational mechanisms, and boundary conditions. Journal of Applied Psychology, 93: 108-124.

Grant, A. M., \& Ashford, S. J. 2008. The dynamics of proactivity at work. In A. P. Brief \& B. M. Staw (Eds.), Research in organizational behavior, vol. 28: 3-34. Greenwich, CT: JAI Press.

Grant, A. M., \& Gino, F. 2010. A little thanks goes a long way: Explaining why gratitude expressions motivate prosocial behavior. Journal of Personality and Social Psychology, 98: 946-955.

Grant, A. M., \& Parker, S. K. 2009. Redesigning work design theories: The rise of relational and proactive perspectives. In J. P. Walsh \& A. P. Brief (Eds.), Academy of Management annals, vol. 3: 317-375. Essex, U.K.: Routledge.

Grant, A. M., Parker, S. K., \& Collins, C. G. 2009. Getting credit for proactive behavior: Supervisor reactions depend on what you value and how you feel. Personnel Psychology, 62: 31-55.

Griffin, M. A., Neal, A., \& Parker, S. K. 2007. A new model of work role performance: Positive behavior in uncertain and interdependent contexts. Academy of Management Journal, 50: 327-347.

Griffin, M. A., Parker, S. K., \& Mason, C. M. 2010. Leader vision and the development of adaptive and proactive performance: A longitudinal study. Journal of Applied Psychology 95: 174-182.

Helgoe, L. A. 2008. Introvert power: Why your inner life is your hidden strength. Naperville, IL: Sourcebooks.

Henriques, I., \& Sadorsky, P. 1999. The relationship between environmental commitment and managerial perceptions of stakeholder importance. Academy of Management Journal, 42: 87-99.

Heslin, P. A., Latham, G. P., \& VandeWalle, D. 2005. The effect of implicit person theory on performance appraisals. Journal of Applied Psychology, 90: 842856.

Hoffman, L. R, \& Maier, N. R. F. 1961. Quality and acceptance of problem solutions by members of homogeneous and heterogeneous groups. Journal of $\boldsymbol{A b}$ normal and Social Psychology, 62: 401-407.

Hofmann, D. A., \& Morgeson, F. P. 1999. Safety-related behavior as social exchange: The role of perceived organizational support and leader-member exchange. Journal of Applied Psychology, 84: 286296.

Hogan, R. 1991. Personality and personality measurement. In M. D. Dunnette \& L. M. Hough (Eds.), Handbook of industrial and organizational psychology, vol. 2: 873-919. Palo Alto, CA: Consulting Psychologists Press.

House, R. J., \& Howell, J. M. 1992. Personality and charismatic leadership. Leadership Quarterly, 3: 81-108.

House, R. J., Shane, S. A., \& Herold, D. M. 1996. Rumors of the death of dispositional research are vastly exaggerated. Academy of Management Review, 21: 203-224.

John, O. P., \& Srivastava, S. 1999. The Big-Five trait taxonomy: History, measurement, and theoretical perspectives. In L. A. Pervin \& O. P. John (Eds.), Handbook of personality: Theory and research (2nd ed.): 102-138. New York: Guilford. 
Johnson, A. M., Vernon, P. A., Harris, J. A., \& Jang, K. L. 2004. A behavior genetic investigation of the relationship between leadership and personality. Twin Research, 7: 27-32.

Jones, D. 2006. Not all successful CEOs are extroverts. USA Today, June. www.usatoday.com/money/companies/ management/2006-06-06-shy-ceo-usat x.htm. Accessed November 9, 2008.

Judge, T. A., Bono, J. E., Ilies, R., \& Gerhardt, M. W. 2002. Personality and leadership: A qualitative and quantitative review. Journal of Applied Psychology, 87: 765-780.

Judge, T. A., Piccolo, R. F., \& Kosalka, T. 2009. The bright and dark sides of leader traits: A review and theoretical extension of the leader trait paradigm. Leadership Quarterly, 20: 855-875.

Kahnweiler, J. B. 2009. The introverted leader: Building on your quiet strength. San Francisco: BerrettKoehler.

Kaiser, R. B., Hogan, R., \& Craig, S. B. 2008. Leadership and the fate of organizations. American Psychologist, 63: 96-110.

Kiesler, D. J. 1983. The 1982 interpersonal circle: A taxonomy for complementarity in human transactions. Psychological Review, 90: 185-214.

Kipnis, D., \& Schmidt, S. M. 1988. Upward-influence styles: Relationship with performance evaluations, salary, and stress. Administrative Science Quarterly, 33: 528-542.

Kirkman, B. L., \& Rosen, B. 1999. Beyond self-management: Antecedents and consequences of team empowerment. Academy of Management Journal, 42: $58-74$.

Kirkpatrick, S. A., \& Locke, E. A. 1991. Leadership: Do traits matter? Academy of Management Executive, 5(2): $48-60$.

Kline, R. B. 1998. Principles and practice of structural equation modeling. New York: Guilford.

Kramer, R. M. 1998. Paranoid cognition in social systems: Thinking and acting in the shadow of a doubt. Personality and Social Psychology Review, 2: 251275.

Kristof-Brown, A., Barrick, M. R., \& Stevens, C. K. 2005. When opposites attract: A multi-sample demonstration of complementary person-team fit on extraversion. Journal of Personality, 73: 935-958.

Laney, M. O. 2002. The introvert advantage: How to thrive in an extrovert world. New York: Workman.

Le, H., Oh., I.-S., Robbins, S. B., Ilies, R., Holland, E., \& Westrick, P. 2011. Too much of a good thing: Curvilinear relationships between personality traits and job performance. Journal of Applied Psychology, 96: 113-133.

Leana, C., Appelbaum, E., \& Shevchuk, I. 2010. Work process and quality of care in early childhood edu- cation: The role of job crafting. Academy of Management Journal, 52: 1169-1192.

Leary, T. 1957. Interpersonal diagnosis of personality. New York: Ronald Press.

LeBreton, J. M., \& Senter, J. L. 2008. Answers to 20 questions about interrater reliability and interrater agreement. Organizational Research Methods, 11: 815-852.

Leung, S. L., \& Bozionelos, N. 2004. Five-factor model traits and the prototypical image of the effective leader in the Confucian culture. Employee Relations, 26: 62-71.

Lipponen, J., Koivisto, S., \& Olkkonen, M.-E. 2005. Procedural justice and status judgments: The moderating role of leader ingroup prototypicality. Leadership Quarterly, 16: 517-528.

Little, B. R., \& Joseph, M. F. 2006. Personal projects and free traits: Mutable selves and well beings. In B. R. Little, K. Salmela-Aro, \& S. D. Phillips (Eds.), Personal project pursuit: Goals, action, and human flourishing: 375-400. Mahwah, NJ: Erlbaum.

Locke, E. A., \& Latham, G. P. 2002. Building a practically useful theory of goal setting and task motivation: A 35-year odyssey. American Psychologist, 57: 705-717.

Lord, R. G., De Vader, C. L., \& Alliger, G. M. 1986. A meta-analysis of the relation between personality traits and leadership perceptions: An application of validity generalization procedures. Journal of Applied Psychology, 71: 402-410.

Lykken, D. 1968. Statistical significance in psychological research. Psychological Bulletin, 70: 151-159.

Magee, J. C., \& Galinsky, A. D. 2008. Social hierarchy: The self-reinforcing nature of power and status. In J. P. Walsh \& A. P. Brief (Eds.), Academy of Management annals, vol. 2: 351-398. Essex, U.K.: Routledge.

Mann, R. D. 1959. A review of the relationships between personality and performance in small groups. Psychological Bulletin, 56: 241-270.

McCormack, L., \& Mellor, D. 2002. The role of personality in leadership: An application of the five-factor model in the Australian military. Military Psychology, 14: 179-197.

McCrae, R. R., \& Costa, P. T., Jr. 1989. The structure of interpersonal traits: Wiggins's circumplex and the five-factor model. Journal of Personality and Social Psychology, 56: 586-595.

McCrae, R. R., \& Costa, P. T., Jr. 1990. Personality in adulthood. New York: Guilford.

McFarlin, D. B., \& Sweeney, P. D. 1996. Does having a say matter only if you get your way? Instrumental and value-expressive effects of employee voice. Basic and Applied Social Psychology, 18: 289-303.

McGregor, I., McAdams, D. P., \& Little, B. R. 2006. Personal projects, life stories, and happiness: On being 
true to traits. Journal of Research in Personality, 40: 551-572.

Miceli, M., \& Near, J. 1995. Effective whistle-blowing. Academy of Management Review, 20: 679-708.

Moon, H., Kamdar, D., Mayer, D. M., \& Takeuchi, R. 2008. Me or we? The role of personality and justice as other-centered antecedents to innovative citizenship behaviors within organizations. Journal of Applied Psychology, 93: 84-94.

Morrison, E. W., \& Milliken, F. J. 2000. Organizational silence: A barrier to change and development in a pluralistic world. Academy of Management Review, 25: 706-31.

Morrison, E. W., \& Phelps, C. 1999. Taking charge: Extrarole efforts to initiate workplace change. Academy of Management Journal, 42: 403-419.

Nemeth, C. J. 1986. Differential contributions of majority and minority influence. Psychological Review, 93: 23-32.

Ng, K.-Y., Ang, S., \& Chan, K.-Y. 2008. Personality and leader effectiveness: A moderated mediation model of leadership self-efficacy, job demands, and job autonomy. Journal of Applied Psychology, 93: 733-743.

Norem, J. K., \& Cantor, N. 1986. Defensive pessimism: Harnessing anxiety as motivation. Journal of Personality and Social Psychology, 51: 1208-1217.

Olson, K. R. 2005. Engagement and self-control: Superordinate dimensions of Big Five traits. Personality and Individual Differences, 38: 1689-1700.

Ones, D. S., \& Dilchert, S. 2009. How special are executives? How special should executive selection be? Observations and recommendations. Industrial and Organizational Psychology, 2: 163-170.

Opt, S. K., \& Loffredo, D. A. 2000. Rethinking communication apprehension: A Myers-Briggs perspective. Journal of Psychology: Interdisciplinary and Applied, 134: 556-570.

Parker, S. K., \& Collins, C. G. 2010. Taking stock: Integrating and differentiating multiple proactive behaviors. Journal of Management, 36: 633-662.

Parker, S. K., Williams, H. M., \& Turner, N. 2006. Modeling the antecedents of proactive behavior at work. Journal of Applied Psychology, 91: 636-652.

Peterson, R. S., Smith, D. B., Martorana, P. V., \& Owens, P. D. 2003. The impact of chief executive officer personality on top management team dynamics: One mechanism by which leadership affects organizational performance. Journal of Applied Psychology, 88: 795-808.

Ployhart, R. E., Lim, B.-C., \& Chan, K.-Y. 2001. Exploring relations between typical and maximum performance ratings and the five factor model of personality. Personnel Psychology, 54: 809-843.

Preacher, K. J., Rucker, D. D., \& Hayes, A. F. 2007. Addressing moderated mediation hypotheses: Theory, methods, and prescriptions. Multivariate Behavioral Research, 42: 185-227.

Ramsay, R. W. 1966. Personality and speech. Journal of Personality and Social Psychology, 4: 116-118.

Rhoades, L., \& Eisenberger, R. 2002. Perceived organizational support: A review of the literature. Journal of Applied Psychology, 87: 698-714.

Rubenzer, S., \& Faschingbauer, T. 2004. Personality, character, \& leadership in the White House: Psychologists assess the presidents. Washington DC: Brassey's.

Rubin, R. S., Munz, D. C., \& Bommer, W. H. 2005. Leading from within: The effects of emotion recognition and personality on transformational leadership behavior. Academy of Management Journal, 48: 845-858.

Scherer, K. R. 1978. Personality inference from voice quality. European Journal of Social Psychology, 8: 467-487.

Schmidt, F. L., \& Hunter, J. 2004. General mental ability in the world of work: Occupational attainment and job performance. Journal of Personality and Social Psychology, 86: 162-173.

Seibert, S. E., Kraimer, M. L., \& Crant, J. M. 2001. What do proactive people do? A longitudinal model linking proactive personality and career success. Personnel Psychology, 54: 845-874.

Shrout, P. E., \& Bolger, N. 2002. Mediation in experimental and non-experimental studies: New procedures and recommendations. Psychological Methods, 7: 422-445.

Smelser, W. T. 1961. Dominance as a factor in achievement and perception in cooperative problem solving interactions. Journal of Abnormal \& Social Psychology, 62: 535-542.

Staw, B. M., \& Boettger, R. D. 1990. Task revision: A neglected form of work performance. Academy of Management Journal, 33: 534-559.

Tamir, M. 2005. Don't worry, be happy? Neuroticism, trait-consistent affect regulation, and performance. Journal of Personality and Social Psychology, 89: 449-461.

Tiedens, L. Z., Chow, R. M., \& Unzueta, M. M. 2007. Complementary contrast and assimilation: Interpersonal theory and the social function of contrast and assimilation effects. In D. Stapel \& J. Suls (Eds.), The social psychology of contrast and assimilation: 249-267. New York: Psychology Press.

Tiedens, L. Z., \& Fragale, A. R. 2003. Power moves: Complementarity in dominant and submissive nonverbal behavior. Journal of Personality and Social Psychology, 84: 558-568.

Trapnell, P. D., \& Wiggins, J. S. 1990. Extension of the Interpersonal Adjective Scales to include the Big Five dimensions of personality. Journal of Personality and Social Psychology, 59: 781-790.

Van Dyne, L., Cummings, L. L., \& McLean Parks, J. 1995. 
Extra-role behaviors: In pursuit of construct and definitional clarity. In L. L. Cummings \& B. M. Staw (Eds.), Research in organizational behavior, vol. 17: 215-285. Greenwich, CT: JAI Press.

Van Dyne, L., \& LePine, J. A. 1998. Helping and voice extra-role behaviors: Evidence of construct and predictive validity. Academy of Management Journal, 41: 108-119.

van Knippenberg, D., \& Hogg, M. A. 2003. A social identity model of leadership effectiveness in organizations. In B. M. Staw \& R. Sutton (Eds.), Research in organizational behavior, vol. 25: 243-295. Greenwich, CT: JAI Press.

van Knippenberg, B., \& van Knippenberg, D. 2005. Leader self-sacrifice and leadership effectiveness: The moderating role of leader prototypicality. Journal of Applied Psychology, 90: 25-37.

Vroom, V. H., \& Yetton, P. W. 1973. Leadership and decision-making. Pittsburgh: University of Pittsburgh Press.

Wall, T. D., Jackson, P. R., \& Davids, K. 1992. Operator work design and robotics system performance: A serendipitous field study. Journal of Applied Psychology, 77: 353-362.

Wiltermuth, S. S. 2009. Dominance complementarity and group creativity. In E. Mannix, J. Goncalo, \& M. Neale (Eds.), Research on managing groups and teams, vol. 12: 87-110. Emerald Group.

Young, T. J., \& French, L. A. 1996. Judged political extroversion-introversion and perceived competence of U.S. Presidents. Perceptual \& Motor Skills, 83: 578.

Yukl, G. 1998. Leadership in organizations. Upper Saddle River, NJ: Prentice Hall.

Zaccaro, S. J. 2007. Trait-based perspectives of leadership. American Psychologist, 62: 6-16.
Adam M. Grant (grantad@wharton.upenn.edu) is an associate professor of management at The Wharton School at the University of Pennsylvania. He received his Ph.D. in organizational psychology from the University of Michigan. His research focuses on work motivation, job design, prosocial helping and giving behaviors, and proactivity and initiative.

Francesca Gino (fgino@hbs.edu) is an associate professor of business administration in the Negotiation, Organizations, \& Markets Unit at the Harvard Business School,
Harvard University. She received her Ph.D. in economics and management from the Sant'Anna School of Advanced Studies. Her research focuses on judgment and decision making, social influence, and ethics.

David A. Hofmann (dhofmann@unc.edu) is a professor of organizational behavior at the University of North Carolina's Kenan-Flagler Business School. He received his Ph.D. from the Pennsylvania State University. His research focuses on leadership, organizational climate, multilevel theory/methods, and safety and human error. 